Portland State University

PDXScholar

$5-2-1978$

Development and Use of a Phonological Recoding

Strategy for a Short-Term Memory Task by Normal and Mentally Retarded Subjects

Mary Jo Bartels

Portland State University

Follow this and additional works at: https://pdxscholar.library.pdx.edu/open_access_etds

Part of the Communication Sciences and Disorders Commons, and the Mental Disorders Commons Let us know how access to this document benefits you.

Recommended Citation

Bartels, Mary Jo, "Development and Use of a Phonological Recoding Strategy for a Short-Term Memory Task by Normal and Mentally Retarded Subjects" (1978). Dissertations and Theses. Paper 2774. https://doi.org/10.15760/etd.2770

This Thesis is brought to you for free and open access. It has been accepted for inclusion in Dissertations and Theses by an authorized administrator of PDXScholar. Please contact us if we can make this document more accessible: pdxscholar@pdx.edu. 
AN ABSTRACT OF THE THESIS OF Mary Jo Bartels for the Master of Science in Speech Communication presented May 2, 1978.

Title: Development and Use of a Phonological Recoding Strategy for a Short-Term Memory Task by Norma1 and Menta11y Retarded Subjects.

APPROVED BY MEMBERS OF THE THESIS COMMITTEE:

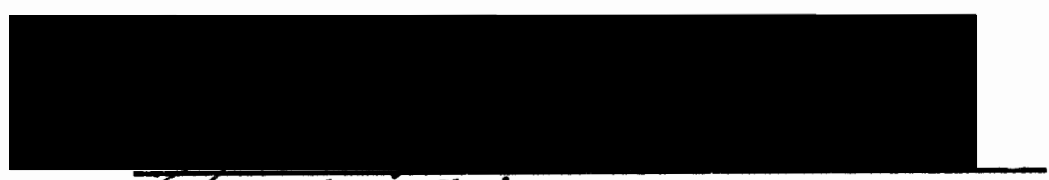

Ioan McMahon, Chairman

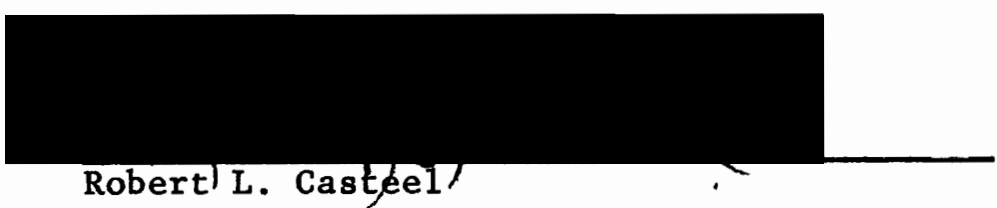

Research has indicated that language, in the form of the "inner language" described by Vygotsky (1962), plays a major mediational role in learning. Researchers have described a "phonological" recoding strategy which seems to develop in normal children with the acquisition of receptive and expressive language ski11s (Conrad, 1971; Sper1ing, 1963; Locke and Kutz, 1975; Wickelgren, 1965; Hintzman, 1967). However, the mentally retarded population has been described as having a "mediational deficiency" (Luria, 1961; Gallagher, 1969; Kendler and Kendler, 1962), although results have not been conclusive. 
The purpose of the present study was to investigate the presence or absence of a phonological recoding strategy in the mentally retarded population by using a memory matching exercise with visual stimuli. Pictures of common objects were divided into eight pictures with names that sound alike (homophonous) and eight with names that do not sound alike (non-homophonous). The null hypothesis tested was:

No statistically significant difference will be found between mentally retarded and normal subjects in the development and use of a phonological recoding strategy for a short-term memory task, when the subjects are matched for receptive vocabulary age.

The younger Receptive Vocabulary Age (RVA) comparison group ( $A_{n}$ ) subjects were the only group that showed evidence of use of a phonological code; therefore, the null hypothesis was rejected. The younger RVA experimental group $\left(A_{m r}\right)$ performed as well as the $A_{n}$ group, but did not use a phonological code. The older RVA comparison group ( $\left.{ }_{n}\right)$ performed better than all the other groups in accordance with their increased language capacity, but they did not exclusively use a phonological code. The older RVA experimental group $\left(\mathrm{B}_{\mathrm{mr}}\right)$ made fewer correct matches, on the average, than all the other groups, and did not use a phonological code.

These results did not conform to the research upon which the present study was based. In explanation, a number of factors must be considered: setting, words used, examiner, and factor held constant. Other factors which may have affected results are: institutionalization, rate of presentation, and the definition of short-term memory that was used.

After all these factors have been considered, it may be postu- 
lated that the difference in scores between groups may have been due to the fact that the mentally retarded group never acquired a "learning set," or never "learned how to learn." This resulted in increasingly deficient performances on learning tasks as the tasks became more difficult. It also may be postulated that the "learning set" related to short-term memory tasks involves as its basis the use of a phonological recoding atrategy, which may predominate in normal children at lower levels of performance and then, as the individual becomes more competent, recede into a more diverse repertoire of learning strategies. This postulation would take Vygotsky one step further. The process of diversification of learning strategies was observed in the comparison subjects but not in the experimental subjects, indicating a qualitative difference in the manner in which the two groups approach a learning task. A quantitative difference in their overall performances also was observed between the two groups. 
DEVELOPMENT AND USE OF A PHONOLOGICAL RECODING STRATEGY FOR A SHORT-TERM MEMORY TASK BY NORMAL AND MENTALLY RETARDED SUBJECTS

\author{
by \\ MARY JO BARTELS
}

A thesis submitted in partial fulfillment of the requirements for the degree of

MASTER OF SCIENCE IN SPEECH COMMUNICATION:

with an emphasis in.

SPEECH PATHOLOGY/AUDIOLOGY

Portland State University

1978 
TO THE OFFICE OF GRADUATE STUDIES AND RESEARCH:

The members of the Committee approve the thesis of Mary Jo Bartels presented May 2, 1978.

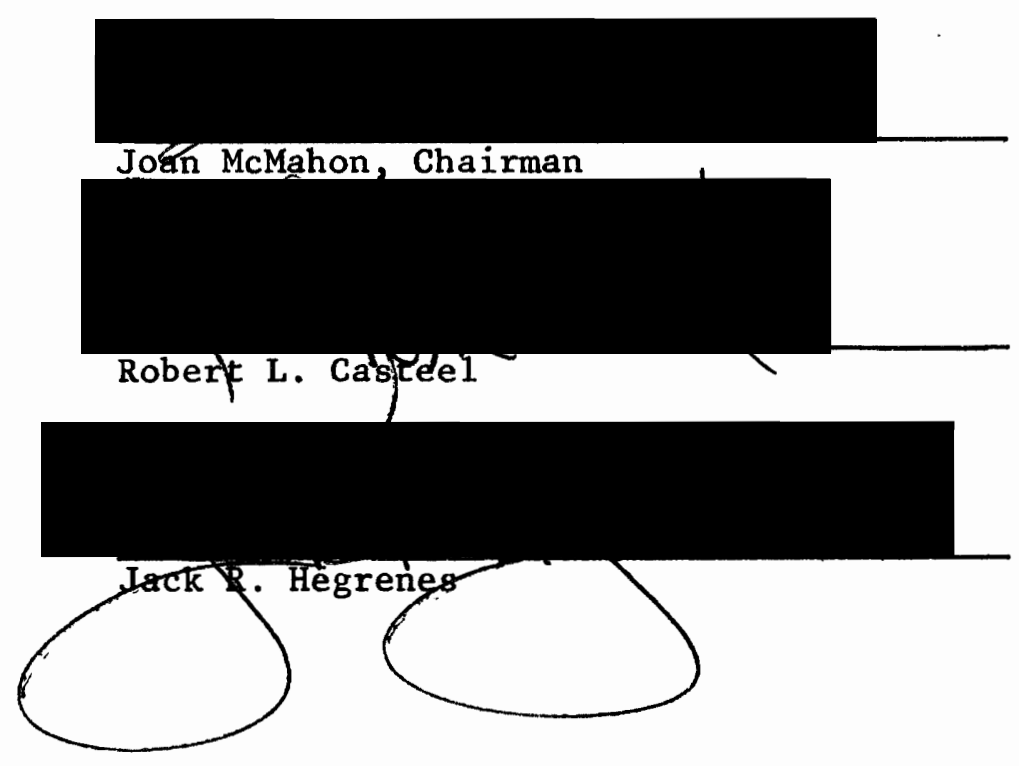

APPROVED :



Robert W. Voge1sapj, Chairmah, Department of Speech Conthunication

Stanley E. Kauch, Dean, Graduate Studies and Research 


\section{ACKNOWLEDGMENTS}

Many people have assisted me in the completion of this research. I would like to sincerely thank my advisor and chairman, Joan McMahon, for her guidance, encouragement, and support. Also, I am grateful to my committee members, Dr. Robert Casteel and Dr. Jack Hegrenes, for their time, their interest, and their counsel, and to Dr. Hegrenes for his statistical expertise.

I owe a debt of gratitude to the program directors, principals, classroom teachers, and parents who offered their cooperation and assistance, providing me with the use of facilities and allowing their students and children to participate in my study. The participants themselves are all very special to me. They each contributed an eagerness and unique character that made it a pleasure to work with them.

And to my husband, Jim, who supported me throughout my graduate education, a very special, warm, and sincere thanks! 
TABLE OF CONTENTS

PAGE

ACKNOWLEDGMENTS

LIST OF TABLES

vi

LIST OF FIGURES

vii

CHAPTER

I INTRODUCTION . . . . . . . . . . . . . . . . . 1

Statement of Purpose . . . . . . . . . . ' 4

Nu11 Hypothesis . . . . . . . . . . . . 4

Operational Definitions . . . . . . . . . . 4

II REVIEW OF THE LITERATURE . . . . . . . . . . . . 6

Definition of Mental Retardation . . . . . .

The Language Factor: Receptive and Expressive Language . . . . . . . . . .

Inner Language . . . . . . . . . . . . 8

Developmental Aspects of Mediation . . . . . . 14

Mediational Deficiency in the Mentally Retarded . 15.

II METHODS AND PROCEDURES . . . . . . . . . . . 20

Subjects . . . . . . . . . . . . . 20

Variables. . . . . . . . . . . . 21

Receptive Vocabulary Age

Auditory and Visual Acuity

Subject Cooperation

Intel1igence

Race

Time of Day 
CHAPTER

PAGE

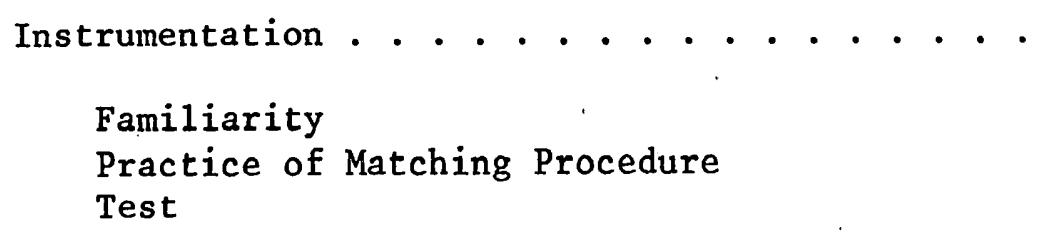

Data Analysis . . . . . . . . . . . . .

IV RESULTS AND DISCUSSION . . . . . . . . . . . .

Resu1ts . . . ................

Intra-Group Comparisons

Inter-Group Comparisons

Discussion . . . . . . . . . . . . .

Intra-Group Comparisons

Inter-Group Comparisons

Correlation of Data

V SUMMARY AND IMPLICATIONS . . . . . . . . . . .

Summary . . . . . . . . . . . . 53

Implications . . . . . . . . . . . 55

Clinical Implications

Implications for Research

SELECTED BIBLIOGRAPHY •. . . . . . . . . . . . . . . 59

APPENDICES . . . . . . . . . . . . . . . . . . 67

A PERMISSION LETTER TO PARENTS . . . . . . . . . . 68

B LINE DRAWINGS USED FOR MATCHING TASK . . . . . . . . 69

C SCHEMATIC REPRESENTATION OF PROCEDURE . . . . . . . . 71 
LIST OF TABLES

TABLE

PAGE

I INTRA-GROUP COMPARISONS SHOWING MEANS, STANDARD DEVIATIONS, AND t-TEST RESULTS FOR NORMAL AND MENTALLY RETARDE $\bar{D}$ GROUP PERFORMANCES ON HOMOPHONOUS AND NON-HOMOPHONOUS WORDS . . . . . . . 30

II INTER-GROUP COMPARISONS SHOWING MEANS, STANDARD DEVIATIONS, AND t-TEST RESULTS FOR NORMAL AND MENTALLY RETARDED GROUP PERFORMANCES ON HOMOPHONOUS AND NON-HOMOPHONOUS WORDS

III RVA SCORES AND TOTAL CORRECT SCORES FOR A $A_{\mathrm{mr}}$ AND $\mathrm{B}_{\mathrm{mr}}$ "INSTITUTIONALIZED" GROUP MEMBERS,

AS COMPARED WITH GROUP MEAN SCORES . • . . . .

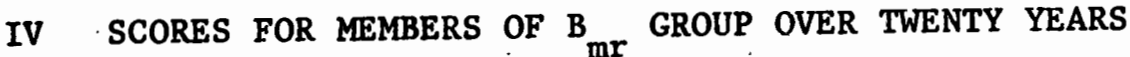
OF AGE . . . . . . . . . . . . . . . . 42

V MEAN SCORES FOR THE HIGHEST RVA LEVEL COMPARISON GROUP AND THE ENTIRE GROUP, ON NH AND H WORDS . . 


\section{LIST OF FIGURES}

1 Intra-group comparisons showing mean correct scores achieved by each group for $\mathrm{NH}$ and $\mathrm{H}$ sets . 34

2 Inter-group comparisons showing mean correct scores achieved by experimental and comparison groups for the $\mathrm{H}$ and $\mathrm{NH}$ sets . . . . . . . .

3 a. Effect on recall as a function of Mental Age when names of items sound alike or unlike (Conrad, 1971). . . . . . . . . . . . . 48

b. Effect on recal1 as a function of RVA when names of items sound alike or unlike ( $A_{n}$ and $B_{n}$ groups), from the present study . . . . . . . 48

4 Mean scores for highest RVA level in B groups compared with mean scores for entire B group . . 


\section{CHAPTER I}

\section{INTRODUCTION}

Deficiency in language development and mental retardation are conditions often associated in a causal connection. Significant delay in language development is included in the American Association on Mental Deficiency's definition of retardation (Grossman, 1973) and measured in the AAMD Adaptive Behavior Scale, 1974 revision (Nihira, Foster, Shellhaas, and Leland, 1974), in terms of receptive and expressive language skills. "Receptive language skills" refers to the perception of the speech code, and "expressive language skills" to articulation of the speech code for meaningful communication. Obviously, effective communication through language is essential for adequate social functioning and personal independence in daily living. Receptive and expressive language skills in the mentally retarded have received some attention, and reviews of research can be found in McLean, Yoder, and Schiefelbusch (1972) and Schiefelbusch, Copeland, and Smith (1967).

A third aspect of language described by Vygotsky (1962) as "inner. language" merits consideration as an essential element in the process of concept formation. Inner language was defined by Vygotsky (1962) as the internal manipulation of linguistic symbols, and forms a basis for. the ability to think, reason, remember, plan, and organize. In contrast to receptive and expressive language, which performs a communica- 
tive function, inner language represents a covert, internal use of language for individual learning.

Because inner language is not readily quantifiable, it is difficult to study. It must be investigated through quantifiable skills which can be attributed to use of language in a mediational capacity between an event and the reproduction of the event. In other words, study of inner language must involve measurement of some overt behavior which can be shown to indicate the use of language to "recode" a stimulus into a symbolic form which facilitates learning. Recall of learned information can be identified as an overt act which signifies that learning has taken place, and speech is often regarded as the expression of the more complex language skill. Therefore, investigation of the internal manipulation of linguistic symbols as a mediator for learning has often been approached in terms of memory tasks, and evidence of verbal recoding sought.

Researchers such as Conrad (1962), Sperling (1963), and Locke and Kutz (1975) have presented subjects with sets of visual stimuli which, a1though not alike in visual form, were alike when acoustic features were considered. Learning of these stimuli was contrasted with learning of visual stimuli having no similar acoustic features. When the subjects were required to recall the stimuli, they tended to make more errors recalling acoustically similar than acoustically dissimilar stimuli. Since in recall a list of similar items produces greater confusion than a list of dissimilar items (McGeoch and McDonald, 1931; Osgood, 1948, 1949; Young, 1955; Gladis and Braun, 1958; Sperling, 1963; Conrad, 1964, 1971, 1972; Wickelgren, 1965; Estes, 1972; Glass- 
man, 1972; Locke and Kutz, 1975), these results were recognized as evidence that a verbal code was used as a retention strategy.

Studies conducted in this manner have generally confirmed the preferential use by normal subjects of a verbal code, termed "phonological code," as a mediational strategy for recall (Conrad, 1964; Corcoran, 1966; Wickelgren, 1965; Hintzman, 1967; Locke, 1970; Locke and Kutz, 1975). Further, in normal subjects this phonological recoding strategy has been found to increase in efficiency with increased mental age (Conrad, 1971; Flave11, Beach, and Chinsky, 1966; Keeney, Cannizzo, and Flavel1, 1967).

Mentally retarded individuals have been described as deficient in verbal mediation strategies (Luria, 1961; O'Connor and Hermelin, 1959; Milgram and Furth, 1963; Rieber, 1964); that is, they are not observed to use verbal recoding to facilitate learning. Studies of the processes underlying mediational activity in the retarded have been inconclusive (Kendler and Kendler, 1962; Borkowski and Johnson, 1968; Penney, Seim, and Peters, 1968; Gallagher, 1969). The existence of a mediational deficiency has not been conclusively documented, nor have the processes used for mediation in learning tasks by the mentally retarded been identified. It is not known whether the mentally retarded population develops learning strategies identical to those of the normal population, but at a delayed rate, or whether it is symptomatic of mental retardation that no strategies are developed at all. 
STATEMENT OF PURPOSE

It was the purpose of this study to investigate the presence or absence of a phonological recoding strategy in the mentally retarded population by using a memory matching exercise with visual stimuli.

Pictures to be matched consisted of acoustically similar and dissimilar sets. Matching was considered the behavioral indication of short-term retention, and analysis was made of the errors in matching. It was assumed that a greater number of errors made with the acoustically similar words indicated that the subject used a verbal recoding strategy for learning under these conditions.

A secondary purpose of this study was to discover a developmental pattern in the emergence of the phonological recoding strategy in the mentally retarded population, if such a strategy was found to be in use.

NULL HYPOTHESIS

The null hypothesis tested in this investigation was:

No statistically significant difference will be found between mentally retarded and normal subjects in the development and use of a phonological recoding strategy for a short-term memory task, when the subjects are matched for receptive vocabulary age.

\section{OPERATIONAL DEFINITIONS}

Following are operational definitions of specific terms employed in this investigation:

Acoustic: Relating to sound; speech as sound. Expressive language: Articulation of the speech code for meaningful 
communication.

Homophonous: Containing acoustically equivalent vowe1 sounds.

Inner language: Internal manipulation of linguistic symbols for concept development.

Phonological Code: A set of acoustic symbols based on the articulation of speech sounds, into which sensory stimuli are restructured for storage and retrieval.

Receptive language: Perception of the speech code.

Recoding: Restructuring of sensory information for efficient storage and retrieval.

Short-term memory: Retention of information presented once and assessed after less than thirty seconds. Assessment consists of observation and recording of behavioral responses which utilize the information originally presented.

Speech decoding: Unlacking of information carried in speech symbols through a process of reconstructing the acoustic pattern to recover information about how the speech signal was articulated.

Speech encoding: Transmission of language in an acoustic pattern determined by the articulation of the speech sounds. 
CHAPTER II

REVIEW OF THE LITERATURE

DEF INITION OF MENTAL RETARDATION

Before intelligence tests were developed, judgment of mental retardation was based on degree of social incompetence. A person was considered "mentally retarded" when he demonstrated inability to function adequately within his environment. Alfred Binet's first measure of intelligence appeared in 1904 for the purpose of identifying children who would not be expected to do well in school. Through misuse the "intelligence" measured in Binet's test came to be regarded as an unalterable human quality, and the "intelligence quotient" used to identify and label children according to supposed intellectual capabilities (Kauffman and Payne, 1975). Recently definitions of mental retardation have been revised to include both intellectual development and adaptive behaviors. The definition of mental retardation adopted by the American Association on Mental Deficiency (AAMD), developed by Heber (1959, 1961) and revised by Grossman (1973), stated:

Mental retardation refers to significantly subaverage general intellectual functioning existing concurrently with deficits in adaptive behavior and manifested during the developmental period.

According to Kauffman and Payne (1975), "subaverage intellectual functioning" refers to a score on an intelligence test, and "adaptive behavior" refers to sensory-motor and self-help skills, socialization, 
academic progress, and communication.

THE LANGUAGE FACTOR: RECEPTIVE AND EXPRESSIVE LANGUAGE

"Communication" is such a multi-dimensional concept that it merits consideration in its own right. Vygotsky (1962) described communication as "a rational, intentional conveying of experience and thought to others," requiring a mediating system he identified as 1anguage. Language, a primary means by which humans communicate (Bloomfield, 1933), is, in turn, a complex behavior difficult to define. Dale (1972) described language as "species specific and species uniform," meaning that it is a behavior with universal characteristics and unique to humans. Pierce (1975) created the definition: "Language is a set of structured vocal symbols," or vocal symbols and a set of rules governing their arrangement into meaningful units. According to McLean et al. (1972), these rules are observable in the differential properties that can be categorized at phonological, morphological, syntactic, and semantic levels. Development of rules for each of these levels is reflected in the child's linguistic maturation and observed in his "receptive" and "expressive" language skills.

Receptive and expressive language can be explained in terms of the "motor theory of speech perception" as discussed in Sanders (1977). Sanders described receptive language as the "decoding" phase and expressive language as the "encoding" phase of a single communicative process. According to the motor theory, the two phases are interrelated in that speech is decoded with reference to the manner in which it was encoded. To support this relationship, Sanders noted that each 
unit of a speech signal individually requires $250 \mathrm{milliseconds}$ processing time by the auditory system, whereas the rate of normal speech allows, at most, only 50 milliseconds processing time for each unit. Based on this data he hypothesized that a phoneme contains "constraint criteria" which allow for anticipation of articulatory movements of subsequent phonemes and the processing of larger amounts of information more rapidly. The constraints consist of allophonic variations of the acoustic patterns of phonemes which forecast context and order of sounds. Thus, the listener relies on stored information about the articulation of speech sounds in order to interpret the acoustic signal. He depends on his knowledge of encoding in order to decode. A direct relationship exists, therefore, between expressive language, or articulation, and receptive language, or the processing of the resultant acoustic signal.

\section{INNER LANGUAGE}

However, expressive and receptive language does not account for the totality of linguistic behavior. In his review McCarthy (1964) discussed the additional concept of "inner language," which he defined as the internal manipulation of linguistic symbols. Less apparent and more difficult to evaluate than expressive and receptive language, inner language has its conceptual roots in Piaget's (1955) theory of egocentric thought. Egocentric thought occupies a position in Piaget's cognitive development concept midway between autistic thought, the first to appear, and socialized thought, the most mature. Autistic thought is said to be subconscious and non-directed, and socialized 
thought was described by Piaget as that which is adapted to and influences reality. Egocentric thought was interpreted by Flave11, Beach, and Chinsky (1966) to be a transformation of intellectual functioning in the pre-operational child from sensori-neural-based overt acts to inner symbolic manipulation of reality. Vygotsky (1962) expanded Piaget's position to include the proposition that egocentrism pervades both the verbal and perceptual spheres. When socialized thinking begins to develop in the child, egocentric features do not disappear, but are transformed into purely verbal thought, or an inner language. At this point words are no longer properties of objects for the child, but symbols. As indicated by Pierce (1975), the symbols of language do not retain the properties of the objects or events they symbolize. So as inner speech develops, language is no longer tied to a concrete situation. Language may be used outside situational context as a bridge between two events, the stimulus event and the response to the stimulus. It is this ability to associate two events through language that forms a basis for the ability to think, reason, remember, plan, and organize (Vygotsky, 1962), in other words, to learn. Indirect associations which link two events more closely together for learning are common1y referred to as "mediators" (E11is, 1974).

Inner language was described by Vygotsky (1962) as "speech for oneself." In contrast to receptive and expressive language, it does not function communicatively; rather, it is essential to the internal process of concept formation. For this reason it is difficult to identify and assess. Investigation is usually approached in terms of memory tasks, since retention and recall of complex stimuli are con- 
sidered an indication of efficient use of a mediator. Miller (1956) offered the concept of "recoding" as the probable system for organizing the information in a stimulus for the most efficient transmission. He concluded that the span of immediate memory, which seems to be limited to seven "chunks" or units of information, severely limits the amount that can be retained for immediate recall. The number of "bits" of information, that is, the various aspects of a stimulus that are included in each chunk, can be increased so each chunk carries an inctreased amount of information. Input events are thus grouped and a new name applied to each group. The new name is remembered rather than the input event. Reviews of Miller's recoding theory and its implications are found in Johnson (1969), Me1ton and Martin (1972), and Mandler (1967).

Miller's memory theory was related to verbal mediation by Glanzer and Clark's (1963) "verba1-loop hypothesis," which suggested that a subject receiving a stimulus describes it to himself verbally and retains this verbalization for recall. The resulting descriptions are not exact replications of the names of the elements themselves, but a set of phrases descriptive of the stimulus patterns. The consequence is a reorganized format in which the stimulus items are not directly related to the recoded elements.

An experimental set that has been widely accepted as an accurate indication of the type of mediating strategy used in retention and recall of stimuli has been analysis of the errors which subjects make when asked to recall stimuli identical in a certain dimension (Sperling, 1963; Conrad, 1964, 1971, 1972; Wickelgren, 1965; Estes, 1972; Glassman, 
1972; Locke and Kutz, 1975). In 1931 McGeoch and McDonald found that for serial learning, when the variable is the semantic similarity between an interpolated 1 ist of words and the original 1ist, a similar interpolated list will produce greater forgetting than a different 1ist. These results were replicated by Osgood (1948, 1949), Young (1955), and Gladis and Braun (1958) for paired-associate learning. To a large extent, studies involving this experimental condition have confirmed the preferential use of a language code for mediation over other possible types of codes. Sperling (1963) investigated visual information storage. He noted that his subjects often made auditory confusions in immediate recall of visual stimuli; that is, when an error was made, it was likely to be among stimuli similar in acoustic properties, even though the stimuli were presented visually. He suggested that this auditory component, probably common to both visual and auditory reproduction tasks, could be the limiting factor which accounts for the span of immediate memory recorded by Miller (1956). Sperling further suggested that verbal recoding is enhanced by verbal rehearsal (repeating the names of the stimuli to oneself), which performs the function of a feedback loop. The loop feeds verbal stimuli back into the storage system long after the visual image has decayed, accounting for the observed preference for a verbal retention strategy over a visual system.

Conrad (1964) demonstrated again that the most likely confusions in an immediate memory task involving visual stimuli are between items that "sound alike" (are verbally produced with identical vowel sounds). He postulated a "phonological code" retained by the subjects so that, 
upon recall of the visual stimuli, confusions occurred between the names that sounded alike rather than the items that looked alike.

The term "phonological code" merits some clarification, since it is a term used quite often in the literature to refer to the function of inner speech in memory. Early studies (Conrad, 1963, 1964; Conrad, Freeman and Hu11, 1965; Corcoran, 1966) referred to "acoustic" properties evident in a recoding strategy, and investigated confusion errors among visually presented consonants. Conrad (1964) found more errors among consonants that "sound alike," that is, share acoustic features, than among those that look alike. It might be presumed the shared "acoustic" features were found in the vowels used to articulate the names of the consonants, as in $/ \mathrm{bi} /, / \mathrm{pi} /$, and $/ \mathrm{d}_{\mathbf{j}} \mathrm{i} /$, or $/ \boldsymbol{\varepsilon f}_{\mathrm{f}} /, / \varepsilon 1 /$, and $/ \mathcal{E m} /$. By 1967 the term "acoustic" had been used in reference to two different types of information received from stimuli: acoustic information corresponding to verbal productions, and articulatory information corresponding to information acquired through the articulatory activity often observed when the subject rehearsed (Cheng, 1974). A controversy arose as to which cues were relevant to recoding of information for recal1 (Hintzman, 1967; Wickelgren, 1965). Morton (1969) first used the term "phonological code" in order to circumvent this controversy. Historically, linguistic analysis was couched in terms of syntax, grammar, and phonology (Pierce, 1975) and undoubtedly it was the phonology of linguistic analysis to which Morton referred. Phonology in this context refers to the sound system of which a language is composed. Linguists studied a language in terms of "acoustic phonetics," or the study of speech as noise, and "articulatory phonetics," or 
the relationship between articulatory movements and speech sounds. With the identification of the phoneme by Bloomfield (1933) as a "minimum unit of distinctive sound-feature," the realization grew that some phonetic features differentiate one word from another while others do not. In reference to this smaller, more precise unit, "phonological code" might be more aptly termed "phonemic code." However, in the interest of consistency with previous terminology, "phonological code" will continue to be used here.

Various other researchers (Wickelgren, 1965; Hintzman, 1967; Locke, 1973; Locke and Kutz, 1975; Liberman, Mattingly, and Turvey, 1972) have supported the concept of a phonological code as the most efficient and most likely recoding strategy for short-term retention of stimuli. Locke and Kutz (1975) review the options: Iconic storage probably holds too few items for too short a time and nonphonetic strategies such as semantic coding and visual imagery call for a more complex organization and encoding time than is most often available. Although it has been shown that other strategies may be used in recall tasks, particularly when phonological code is not available, for instance, when the subjects are deaf (Conrad and Rush, 1965; Conrad, 1972), the fact remains that greater recall is likely to result with the opportunity for the rehearsal associated with phonological recoding (Rundus and Atkinson, 1970; Rundus, 1971; Estes, 1972; Keeney, Cannizzo, and Flave11, 1967; Cole, Coltheart, and Allard, 1974). 


\section{DEVELOPMENTAL ASPECTS OF MEDIATION}

Consistent with the developmental pattern traced by Piaget (1955) and Vygotsky (1962) for maturation of language skills, the mediational function of inner language has been shown to develop chronologically in normal children (Youniss and Furth, 1963; Flave11 et a1., 1966; Keeney et a1., 1967). According to the data of these researchers, normal children tend not to mediate or regulate their overt behavior verbally prior to about five years of age, even though they have acquired the necessary verbal proficiency. On the basis of considerable evidence, Reese (1962) proposed.a "mediational deficiency hypothesis" which stated that up to a certain stage in development, the child tends not to employ verbal mediation, but linguistic and non-linguistic behavior undergoes developmental changes and the ability to use language in a mediational capacity increases. Conrad (1971) found no evidence indicating that a child under the age of five uses a verbal code in mediation for recall, but after five years of age the mediational capacity of the child increases so that by eight to eleven years the child will use a verbal code almost 100 percent of the time. Reese (1962) suggested that mediation may be a "voluntary" process, related to internal verbal rehearsal of items for recall. If verbal mediation is a learned skill, then instruction in the use of the process should positively affect mnemonic skills and, therefore, increase learning capacity.

Based partly on Reese's data and conclusions, Flavell et a1. (1966) developed a "production deficiency hypothesis" which suggested that the younger child's difficulty lies in a failure to produce inner speech at all. In other words, the child is deficient in producing 
mediational language. The production deficiency hypothesis was confirmed by Flavell et a1. in the 1966 study, and supported by Keeney et al. (1967), Ellis (1970), and Locke and Kutz (1975).

It is not difficult to recognize other populations to which the production deficiency hypothesis might apply. Certainly the deaf population does not have immediate reference to a verbal code for mediational use, and studies have been undertaken to investigate alternative codes available to them (Conrad, 1972; Locke and Locke, 1971). The mentally retarded represent another such population.

\section{MEDIATIONAL DEFICIENCY IN THE MENTALLY RETARDED}

The Russian researcher and student of Vygotsky, A. R. Luria, proposed a verbal mediation deficit in the retarded as a result of his observation that retarded children, like normal children of a lower chronological age, experience difficulty in tasks which require "dissociation" of the verbal system from external behavior (Luria, 1961). Early research on this topic was divided into support for Luria's position (0'Connor and Hermelin, 1959; Milgram and Furth, 1963; Rieber, 1964) and opposition (Balla and Zigler, 1964; Berkson and Cantor, 1960). Contradictory findings led Borkowski and Wanschura (1974) to conclude, "It would seem that the imprecision of Luria's theory makes direct, unequivocal assessment impossible."

Studies to prove or disprove the existence of a verbal mediational deficit in retarded individuals may, therefore, be of less value than the study of the processes underlying the mediational activity. Jensen (1971) grouped the tasks most often used to assess mediation into 
eleven categories ranging from discrimination learning and semantic generalization to experimentally acquired mediators and mnemonic elaborations. In some tasks the mediator under study was not directly manipulated or under the control of the experimenter. Kendler and Kendler (1962); for example, employed a discrimination learning task, assuming evidence of mediational limitations in those subjects who did not acquire reversal shifts as easily as others. In other tasks mediators supplied by the experimenter were presumed to bring the mediational process under more external control. Borkowski and Johnson (1968) used a three-stage chaining condition in which subjects learned $A-B$ and $B-C$ links, then were tested for $A-C$ learning. When mediating links were provided, the retarded group performance approached or equalled that of the comparison group of normal children matched for mental age, although normal children performed better in the control condition.

Although direct manipulation of internal events, represented by (but not limited to) three-stage chaining studies, is considered to increase the probability of test validity, findings from such studies have not been conclusive. Penney, Seim, and Peters (1968) presented data that suggested that no mediational deficiency exists at all in retarded children relative to normal children of the same mental age. They used a three-stage chaining task, varying test interval times, and found that as intervals were increased, the retarded group seemed to show increased benefits from mediational aids. In fact, at longer intervals, mediation was facilitated in the retarded group but eliminated for the normal children. 
Gallagher (1969) focused on language used in mediation, employing a task which manipulated strengths of associations formed through natural language habits, rather than associations formed artificially or in the laboratory. He found that normal subjects matched for Mental Age with the retarded group made fewer errors than retarded subjects under all conditions, and suggested that perhaps the natural language mediators were not as readily available to the retarded subjects. Thus, he linked the mediational deficiency hypothesis and the theory of maturational development of inner language. Vygotsky (1962) suggested that use of inner language in a mediational capacity requires development of language skills beyond a concrete, operational level. Various studies reviewed by Jordan (1967) have indicated that language in retarded individuals generally fails to develop beyond a concrete conceptual level. Gallagher presented evidence to show that menţally retarded individuals will be expected to experience difficulty in acquiring the capacity to evoke a signifier (word) to symbolize any outside event, or to use language to recode an event for retention and reca11.

It appears that extensive further study must be done to identify and describe a mediational deficiency in the mentally retarded population. Not until a mediational strategy and its parameters are defined can researchers turn their attention to development of techniques for improving learning capacity through improved learning strategies. Studies already accomplished give rise to questions covering a broad spectrum. Some of the most interesting questions revolve around the use of natural language mediators in mentally retarded children as com- 
pared with normal children. Do mentally retarded individuals develop verbal mediators for learning as normal individuals seem to, spontaneously, preferentially, and as a function of maturation? Do they develop alternative, less efficient strategies as a result of a general developmental lag in language skills? Do they fail to develop any mediational strategy at a11?

To assure that the processes studied are the same for the mentally retarded and normal populations, both should be administered the same tasks under the same conditions. This is difficult in two populations with such differing ability levels; however, Conrad's (1971) procedure seems to be particularly well suited to that task. His study dealing with the development of covert speech for short-term memory tasks required a procedure applicable to children within a wide age range. He explored the development of a verbal mediation strategy in children by using the similarity confusion paradigm. Subjects from three to five years Mental Age (MA) as established by the English Picture Vocabulary Test (Brimer and Dunn, 1962) demonstrated no efficient verbal recoding of names of visual stimuli for immediate recall, although names of the stimuli were available to them. After five years MA, however, phonological similarity of the stimuli began to make a difference in responses, and the difference increased with the children's increased MA until at eleven years MA performance on names which did not share phonological features reached almost 100 percent: Conrad concluded that in normal children older than age five covert verbalizing is used beneficially in memorizing, problem solving, and learning. The same verbal mediational process in mentally retarded subjects 
seems most appropriately analyzed in terms of the behavior of normal subjects. It was, therefore, the intention of this study to duplicate Conrad's 1971 data, within reasonable limits, with a population of mentally retarded individuals, to establish whether a phonological recoding strategy exists in their repertoire of learning behaviors. 


\section{CHAPTER III}

METHODS AND PROCEDURES

The present study involved twenty mentally retarded individuals and twenty-four normal individuals. Subjects were screened to determine levels of receptive vocabulary, auditory and visual acuity, subject cooperation, intelligence, and race.

\section{SUBJECTS}

Twenty mentally retarded subjects contacted through residential facilities, group homes, and public school special achievement classrooms in the Portland area were randomly selected from a subject pool of sixty-five. Twelve of these twenty subjects demonstrated Receptive Vocabulary Ages (RVA) of 8 years, 1 month, to 10 years, 10 months, as determined by the Peabody Picture Vocabulary Test, Form A (Dunn, 1959). Mean RVA for this group was 9 years, 6 months, the median RVA 9 years, 5 months. Eight subjects demonstrated RVA's of 6 years, 1 month, to 6 years, 10 months, with mean RVA 6 years, 6 months, and median 6 years, 7 months.

Twenty-four comparison subjects were selected from elementary schools in the Portland area using a random sampling table from a subject pool of 187. Fourteen subjects demonstrated RVA's of 8 years, 1 month, to 10 years, 10 months, as determined by the Peabody Picture Vocabulary Test, Form A (Dunn, 1959). Mean RVA was 9 years, 5 months, 
as was the median RVA. Ten subjects demonstrated RVA's of 6 years, 1 month, to 6 years, 10 months, with mean RVA 6 years, 6 months, and median 6 years, 8 months.

\section{VARIABLES}

Variables controlled were receptive vocabulary age, auditory and visual acuity, subject cooperation, intelligence, race, and time of day during which the test was administered. Sex was not controlled since conclusive data have not been presented to show that language development differs significantly at the ages tested as a function of the sex of the individual (McCarthy, 1946; Templin, 1957; Fraser, 1975; Cherry, 1976).

Receptive Vocabulary Age

The Peabody Picture Vocabulary Test, Form A (Dunn, 1959), was administered to each subject, and the RVA score was derived according to data presented in the test manual. The Peabody Picture Vocabulary Test (PPVT) is widely accepted as a measure of RVA, even though it has been called into question as a measure of IQ (Kaufman and Ivanoff, 1968; Williams, Marks, and Bialer, 1977). Since the task described in this study was a receptive task measuring language skills, the PPVT score was considered an appropriate criterion for grouping. Mentally retarded children scoring from 6 years, 1 month, to 6 years, 10 months, RVA constituted Group $A_{m r}$, and those scoring from 8 years, 1 month, to 10 years, 10 months, RVA made up Group $\mathrm{B}_{\mathrm{mr}}$. Normal children scoring from 6 years, 1 month, to 6 years, 10 months, RVA were Group $A_{n}$, and those scoring from 8 years, 1 month, to 10 years, 10 months, RVA were 
Group $B_{n}$.

Auditory and Visual Acuity

Each subject selected for this study was considered to have normal hearing for speech and normal visual acuity on the basis of consultation with classfoom teachers of program directors and informal observation by the examiner. No subjects were eliminated for inadequate hearing acuity. Two subjects were eliminated during initial screening because of insufficient visual acuity. Corrective lenses were allowed.

\section{Subject Cooperation}

Ability of each subject to remain under stimulus control was determined by observation by the examiner during administration of the PPVT. Subjects were required to remain under stimulus control for the duration of the test in order to be considered potential subjects for the study. No subjects were eliminated because of non-cooperation.

\section{Intel1igence}

Experimental group subjects were considered for this study on the basis of a medical diagnosis of mental retardation and their participation in group homes, residential facilities, and special achievement classrooms. Comparison subjects were considered for the study on the basis of their participation and adequate functioning in regular classrooms in the public and parochial school systems and as a result of consultation with the classroom teachers. 
$\underline{\text { Race }}$

Al1 subjects were white. Because the PPVT has been questioned as an appropriate instrument for use with other races, they were not represented (Krescheck and Nicolos, 1973).

Time of Day

A11 participants were examined between 9:00 A.M. and 4:00 P.M. Three experimental group subjects were eliminated because they were the on1y subjects examined after 4:00 P.M. and the fatigue factor was judged to have had undue influence on their scores.

\section{INSTRUMENTATION}

The experimental task consisted of matching black-and-white line drawings of common objects (see Appendix B). Familiarity with names of the objects pictured was established for each subject prior to administration of the test. Test sets of pictures were presented on $3 \times 5$ inch laminated cards. There were two sets of eight cards each. One set consisted of pictures of one-syllable words with identical vowel sounds (rat, fan, hat, bat, man, cat, can, pan), which were considered "homophonous" words. The remaining set consisted of pictures of one-syllable words which were not similar in any way (fish, nail, leaf, spoon, house, bird, coat, dog) and were considered "non-homophonous" words. Display sets of pictures were presented together on cardboard strips. Pictures were randomly placed on the cardboard, and the display strips consisted of eight random arrangements for each set of words. A strip of plain cardboard was used to cover the pictures until the individual picture sets were displayed. 
Each subject was examined individually at the institution through which he was contacted, either group home, residential facility, or school. In a quiet room, with minimal distractions, examiner (E) was seated directly across a small table from each subject (S). The task consisted of three sections: 1) establishing familiarity with the names of the pictures, 2) practice of the procedure of matching, and 3) performing the task. (Schematic representation of procedure is shown in Appendix C.) The entire procedure took approximately one-half hour on the average, and was completed in one sitting.

\section{Familiarity}

One display set of homophonous pictures was placed facing $S$ : For each picture $\mathrm{E}$ instructed, "Show me the ." S was required to point to the named picture. If $S$ failed to respond within ten seconds, the same stimulus was repeated. Failure to respond within ten seconds after the second stimulus, or incorrect identification of any picture, resulted in elimination of $S$ from the study. No subjects were eliminated as a result of this procedure.

Then, as each picture was pointed out by $E, S$ was asked, "What is this?" This procedure determined whether $S$ was supplying a different label for any picture in spite of E's supplying the desired 1abel. If S incorrectly identified any picture (supplied a different label than the one preferred), E instructed, "No, this is ." After the other pictures were identified, $E$ then returned to the mislabelled picture and repeated the stimulus. If, after instruction, s supplied different labels for more than two pictures, he was eliminated from the study. Conrad (1971) did not control for this possibility; however, he dealt 
with the two consistent labelling substitutions which occurred in his study by arguing that, "This would not be enough to equate the sets for difficulty if the children were using a verbal code to memorize them." No subjects were eliminated as a result of this procedure. Familiarity was estab1ished in the same manner for the non-homophonous words. A social reinforcer ("good") was used on a continuous reinforcement schedule.

\section{Practice of Matching Procedure}

One display set of non-homophonous pictures was placed on the table facing S. E drew two random cards from the test non-homophonous set and placed them, face up, between $S$ and the display set, saying, "Look at the and the ." E then slid each picture, face up, under the matching picture in the display set, saying, "__ goes with , and goes with ." E replaced the test cards between $S$ and the display set, and instructed, "You do it. Where do they go?" $\mathrm{S}$ was required to slide the test cards, without picking them up, into position under the matching card in the display set. $S$ was restrained from picking the cards up because of the tendency to turn them over and look at them during the actual test procedure. If $\mathrm{S}$ failed to respond appropriately, E instructed by physically manipulating S's hand, and repeated the task. If $\mathrm{S}$ failed to respond after instruction, $\mathrm{S}$ was eliminated from the study. No subjects were eliminated as a result of this procedure. Time limit for response was ten seconds. Reinforcement was social on a continuous schedule. Test cards were not replaced, and two more cards were drawn randomly from the duplicate set and the task repeated until all eight cards had been used once (four 
trials). Modelling of the procedure by $E$ was not repeated after the first trial if $S$ responded correctly with no further instruction.

One display set of homophonous words was then placed face up, facing $S$, and covered with a strip of cardboard. Two pictures were randomly drawn from the test set and placed face up between $S$ and the display set. S's attention was drawn to the pictures by E's instruction, "Look at the and the ." E then instructed, "Watch. I'm going to turn them over." E turned the cards face down, then asked, "Now where do they go?" E removed the strip of cardboard from the display set. S was required to slide the test pictures, face down, without picking them up, into position under the matching card in the display set. E then turned the cards over to expose the match. A social reinforcer was used for correct response on a continuous reinforcement schedule. If the match was not correct, E instructed, "No, goes with __, and placed the cards in the correct position. S was given another trial with the same cards. If the response was still incorrect, $S$ was eliminated. No subjects were eliminated as a result of this procedure. Cards were not replaced, and the task was repeated until all cards were used (four trials).

$\underline{\text { Test }}$

One homophonous display set was placed face up, facing $S$, and the cardboard strip placed over it. A number of cards was chosen from the test set according to a design which assured that all cards were used equally often and also equally in each serial position. The number of cards displayed was established in the pilot study as the number with the highest probability of evoking a 50 percent correct response rate 
for the homophionous set. Five cards were displayed for the eight- to eleven-year RVA group, and three cards for the six-year age group. Number of cards was varied in order to equalize the difficulty of the task for subjects with varying ability levels. Attention was drawn to the test cards, and the task proceeded as practiced. The test cards were turned face down, and the subject given an eight- to ten-second opportunity for rehearsal. The cardboard strip was then removed from the display set, and the subject instructed to match the cards. E ta1lied each response as correct or incorrect. The six-year age group received twenty-four trials and the eight- to eleven-year age group forty trials for each set, homophonous and non-homophonous. Total number of trials was forty-eight for the younger group and eighty for the older group. Each match counted as one response. No reinforcer was given for correct response, but encouragement such as "Good working" was given intermittently throughout the task.

\section{DATA ANALYSIS}

Subjects were divided for analysis into the following groups: "Group A $A_{n}$ " signified the comparison subjects who received RVA scores from the PPVT of 6 years, 1 month, to 6 years, 10 months. $N=$ 10.

"Group A ${ }_{\mathrm{mr}}$ " signified the experimental subjects who received RVA. scores from the PPVT of 6 years, 1 month, to 6 years, 10 months. $N=$ 8.

"Group $B_{n}$ " signified the comparison subjects who received RVA scores of 8 years, 1 month, to 10 years, 10 months. $N=14$. 


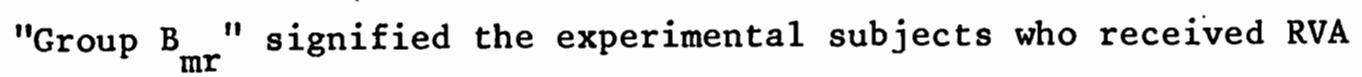
scores of 8 years, 1 month, to 10 years, 10 months. $N=12$.

Data was analyzed in terms of $\underline{t}$-tests to determine the relationship between number and type of errors made by Groups A and B. Groups $A_{n}$ and $A_{m r}$, and Groups $B_{n}$ and $B_{m r}$ were compared to discover similarities and differences in performance of mentally retarded and normal groups. Groups $A_{n}$ and $B_{n}$, and Groups $A_{m r}$ and $B_{m r}$ were compared to discover any developmental pattern. Performances on homophonous words were compared with performances on non-homophonous words to discover evidence of use of a phonological recoding strategy.

The analysis yielded $t$-values which were tested by referring to a normal distribution table to determine the probability associated with the occurrence of values as extreme as the observed $t$. The leve1 of significance used was .05 . If the probability (p) associated with the $\underline{t}^{-v a l u e}$ yielded by the analysis was $\leq .05$, the mean scores for the two groups analyzed were considered significantly different. If $\mathrm{p} \leq .05$, therefore, the statistical inference could be made that the observed difference in performance between the two samples was great enough not to have occurred merely by chance; that is, the probability that the difference in scoring occurred by chance was less than five in one hundred.

Since the questions posed in the research regarding the difference in scores between two samples indicated the predicted direction of the difference, a one-tailed test was used. 


\author{
CHAPTER IV \\ RESULTS AND DISCUSSION
}

RESULTS

This experimental study was conducted to investigate and compare the development and use of a phonological recoding strategy in mentally retarded and normal individuals. Each subject selected for the study was evaluated using the instrument described in Chapter III. The data from this evaluation was analyzed through application of $\underline{t}$-tests yielding intra- and inter-group comparisons. These results will be discussed relative to the proposed null hypothesis, the statistical procedures and descriptive analysis applied to the data, and the results they produced.

The nu1l hypothesis tested was:

No statistically significant difference will be found between mentally retarded and normal individuals in the development of a phonological recoding strategy for a short-term memory task, when the subjects are matched for receptive vocabulary age.

\title{
Intra-Group Comparisons
}

Means, standard deviations, and $\underline{t}-v a l u e s$ for the intra-group comparisons are presented in Table I. These figures show a significant difference in performances, by the same group, on the homophonous (H) and non-homophonous $(\mathrm{NH})$ words only in the $A_{n}(N H) \times A_{n}(H)$ comparison. On the basis of this data, the null hypothesis was rejected for the A 
groups but accepted for the $A_{m r}$ and B groups. Specifically, there is a significant difference in the use of a phonological recoding strategy between normal and mentally retarded subjects of Receptive Vocabulary Age (RVA) 6 years, 1 month, to 6 years, 10 months, but no significant difference for normal and mentally retarded subjects of RVA 8 years, 1 month, to 10 years, 10 months.

TABLE I

INTRA-GROUP COMPARISONS SHOWING MEANS, STANDARD DEVIATIONS, AND t-TEST RESULTS FOR NORMAL AND MENTALLY RETARDED GROUP

PERFORMANCES ON HOMOPHONOUS AND

NON-HOMOPHONOUS WORDS

\begin{tabular}{|c|c|c|c|c|c|c|}
\hline Comparison & $\begin{array}{l}\text { Group } \& \\
\text { Set }\end{array}$ & Mean & S.D. & D.F. & $\frac{t-}{\text { Value }}$ & Result \\
\hline$A_{n}(N H) \times A_{n}(H)$ & $\begin{array}{l}A_{n}(N H) \\
A_{n}^{n}(H)\end{array}$ & $\begin{array}{l}19.80 \\
16.60\end{array}$ & $\begin{array}{l}3.58 \\
3.56\end{array}$ & 18 & 2.00 & $p<.05$ \\
\hline $\mathrm{A}_{\mathrm{mr}}(\mathrm{NH}) \times \mathrm{A}_{\mathrm{mr}}(\mathrm{H})$ & $\mathrm{A}_{\mathrm{mr}}{ }_{(\mathrm{H})}^{(\mathrm{NH})}$ & $\begin{array}{l}15.38 \\
14.50\end{array}$ & $\begin{array}{l}6.95 \\
3.42\end{array}$ & 14 & 0.32 & $\mathrm{p}>.05$ \\
\hline$B_{n}(N H) \times B_{n}(H)$ & $\begin{array}{l}\mathrm{B}_{\mathrm{n}}(\mathrm{NH}) \\
\mathrm{B}_{\mathrm{n}}(\mathrm{H})\end{array}$ & $\begin{array}{l}24.14 \\
22.14\end{array}$ & $\begin{array}{l}9.65 \\
5.65\end{array}$ & 26 & 0.67 & $\mathrm{p}>.05$ \\
\hline$B_{m r}(N H) \times B_{m r}(H)$ & $\begin{array}{l}\mathrm{B}_{\mathrm{mr}}(\mathrm{NH}) \\
\mathrm{B}_{\mathrm{mr}}(\mathrm{H})\end{array}$ & $\begin{array}{l}11.58 \\
10.25\end{array}$ & $\begin{array}{l}5.50 \\
4.11\end{array}$ & 22 & 0.67 & $p>.05$ \\
\hline
\end{tabular}

Data in Table I may be explained thus:

The performance of Group $A_{n}$ on the $\mathrm{NH}$ portion of the matching task was compared with the same group's performance on the H portion. P was found to be $<.05$, indicating that this group performed significantly better in matching $\mathrm{NH}$ words than $\mathrm{H}$ words.

The performance of Group $\mathrm{A}_{\mathrm{mr}}$ on the $\mathrm{NH}$ portion of the task was 
compared with the same group's performance on the $H$ portion. $P$ was found to be $>.05$, indicating that there was no significant difference between the scores this group achieved in matching either $\mathrm{NH}$ or $\mathrm{H}$ words.

The performance of Group $B_{n}$ on the $\mathrm{NH}$ portion of the task was compared with the same group's performance on the H words. P was found to be $>.05$, indicating that performance of this group was not significantly different when matching either $\mathrm{NH}$ or $\mathrm{H}$ words.

The performance of Group $\mathrm{B}_{\mathrm{mr}}$ on the $\mathrm{NH}$ portion of the task was compared with the same group's performance on the H portion. $P$ was found to be $>.05$, indicating that this group did not achieve significantly higher scores when matching $\mathrm{NH}$ words than when matching $\mathrm{H}$ words.

\section{Inter-Group Comparisons}

Means, standard deviations, and the $t$-values relative to the inter-group comparisons are presented in Table II. These figures show a significant difference in overall performance between the 8 to 11 year $B_{n}$ and $B_{m r}$ groups, but no significant difference in overall performance between the 6 to 7 year $A_{n}$ and $A_{m r}$ groups. This information leads to a rejection of the null hypothesis for the $B_{n} \times B_{m r}$ condition, even though the nu11 hypothesis was accepted for that condition in the intra-group comparisons. Although no significant difference was found between the $B_{n}$ and $B_{m r}$ group performances when $N H$ and $H$. comparisons were made, there was a significant difference in their overall performances. The $\mathrm{B}_{\mathrm{n}}$ group achieved considerably higher scores than the $\mathrm{B}_{\mathrm{mr}}$ group. Therefore, members of the two groups cannot be assumed to be using the same strategies in the same manner for this short-term memory 
task, and the null hypothesis must be rejected.

For the $A_{n} \times A_{m r}$ comparison, the null hypothesis has already been rejected on the basis of a difference in performance on $\mathrm{NH}$ words versus $\mathrm{H}$ words condition. Therefore, although no significant difference was found in overall performance, the two groups may be assumed to have used different strategies for this memory task.

\section{TABLE II}

INTER-GROUP COMPARISONS SHOWING MEANS, STANDARD DEVIATIONS, AND t-TEST RESULTS FOR NORMAL AND MENTALLY RETARDED GROUP PERFORMANCES ON HOMOPHONOUS AND NON-HOMOPHONOUS WORDS

\begin{tabular}{|c|c|c|c|c|c|c|}
\hline Comparison & $\begin{array}{l}\text { Group \& } \\
\text { Set }\end{array}$ & Mean & S.D. & D.F. & $\frac{t-}{\text { value }}$ & Result \\
\hline$A_{n}(H) \times A_{m r}(H)$ & $\begin{array}{l}A_{n}(H) \\
A_{m r}(H)\end{array}$ & $\begin{array}{l}16.60 \\
14.50\end{array}$ & $\begin{array}{l}3.56 \\
3.42\end{array}$ & 16 & 1.27 & $P>.05$ \\
\hline$A_{n}(N H) \times A_{m r}(N H)$ & $\begin{array}{l}A_{n}(N H) \\
A_{m r}(N H)\end{array}$ & $\begin{array}{l}19.80 \\
15.38\end{array}$ & $\begin{array}{l}3.58 \\
6.95\end{array}$ & 16 & 1.63 & $\mathrm{p}>.05$ \\
\hline$B_{n}(H) \times B_{m r}(H)$ & $\begin{array}{l}B_{n}(H) \\
B_{m r}(H)\end{array}$ & $\begin{array}{l}22.14 \\
10.25\end{array}$ & $\begin{array}{l}5.65 \\
4.11\end{array}$ & 24 & 6.19 & $\mathrm{p}<.0005$ \\
\hline $\mathrm{B}_{\mathrm{n}}(\mathrm{NH}) \times \mathrm{B}_{\mathrm{mr}}(\mathrm{NH})$ & $\begin{array}{l}\mathrm{B}_{\mathrm{n}}(\mathrm{NH}) \\
\mathrm{B}_{\mathrm{mr}}(\mathrm{NH})\end{array}$ & $\begin{array}{l}24.14 \\
11.58\end{array}$ & $\begin{array}{l}9.65 \\
5.50\end{array}$ & 24 & 4.14 & $\mathrm{p}<.0005$ \\
\hline
\end{tabular}

Data in Table II may be explained thus:

- The overall performance (total correct) on the $H$ set of words by Group $A_{n}$ was compared with that of Group $A_{m r}$. P was determined to be $>.05$, and no significant difference was found between the total number correct for each group.: This value indicates that the ability of the lower RVA mentally retarded sample to match pictures of acoustically 
similar words from memory was not significantly different from the same ability of the comparison sample.

The mean overall performance (total correct) on the $\mathrm{NH}$ set of words by Group $A_{n}$ was compared with that of Group $A_{m r}$. $P$ was found to be $>.05$, indicating that the performance on $\mathrm{NH}$ words by the two groups was not significantly different. However, the $\underline{t}$-value lacked only .112 of the value which would have fallen at $\leq .05$ on the normal distribution table, indicating that the figures trend. The $A_{n}$ group did not perform significantly better on the $\mathrm{NH}$ set than the $\mathrm{A}_{\mathrm{mr}}$ group, but this sample showed a trend in that direction.

The mean total correct on the $H$ set of words achieved by Group $B_{n}$ was compared with that of Group $B_{m r} \cdot P$ was determined to be $<.0005$, indicating that the performance on the $\mathrm{H}$ set of words by Group $B_{n}$ was significantly better than the performance of Group $B_{\mathrm{mr}}$. The probability that this difference occurred by chance is less than 5 in 100,000 .

The mean total correct on the $\mathrm{NH}$ set of words achieved by Group $B_{n}$ was compared with that of Group $B_{m r}$. $P$ was found to be $<.0005$, indicating that the performance on the $\mathrm{NH}$ set of words by Group $\mathrm{B}_{\mathrm{n}}$ was significantly better than the performance of Group $B_{m r}$. The probabi1ity that this difference occurred by chance is less than 5 in 100,000 .

\section{DISCUSSION}

Data obtained from these population samples yielded information which leads to rejection of the null hypothesis. No evidence was discovered to indicate conclusively that mentally retarded subjects develop a phonological recoding strategy for short-term memory tasks in 
the same manner as normal subjects.

\section{Intra-Group Comparisons}

Mean correct scores achieved by each group for $\mathrm{NH}$ and $\mathrm{H}$ conditions are shown in Figure 1 . The comparison group $A_{n}$ (RVA $=6$ years, 1 month, to 6 years, 10 months) performed significantly better on the NH (acoustically dissimilar) set of words than on the $\mathrm{H}$ (acoustically similar) set. According to the data reported in Chapter II, which used analysis of errors made in remembering similar and dissimilar lists, a poorer performance on acoustically similar words would indicate acoustic confusion and, therefore, the use of a phonological recoding strategy. These conclusions may be expressed in the following

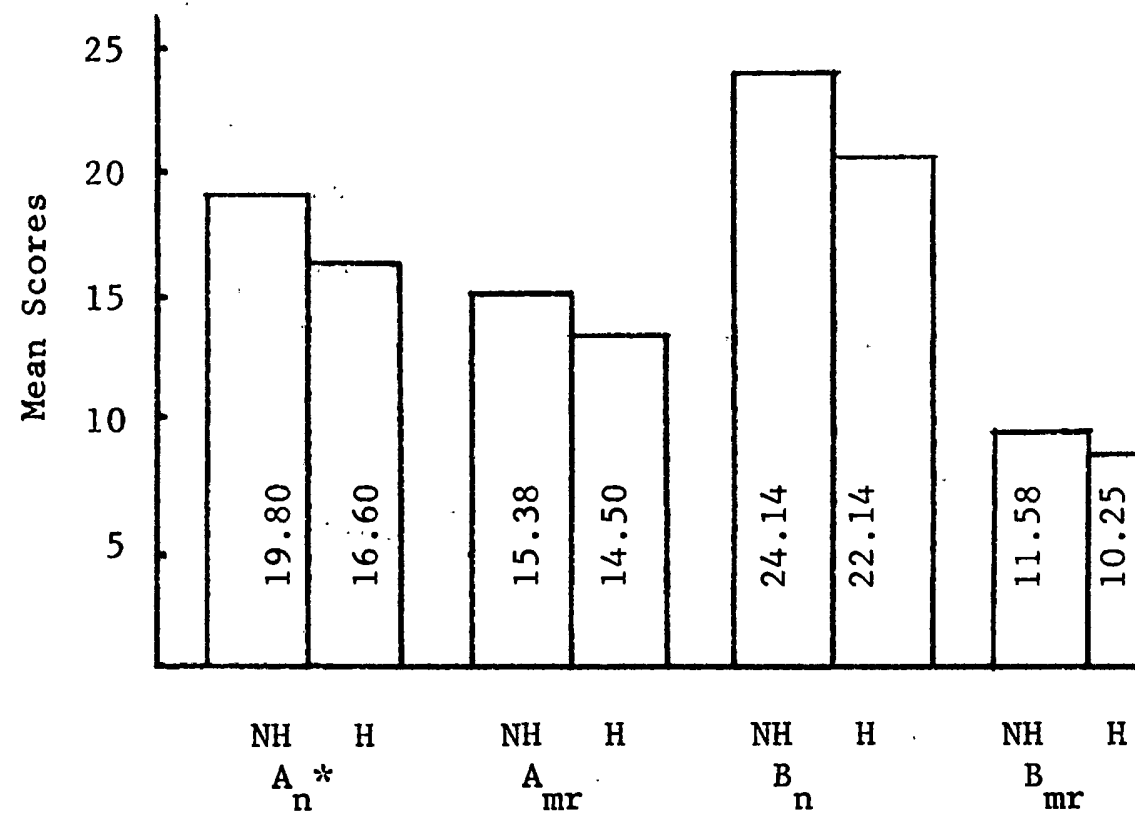

Figure 1. Intra-group comparisons showing mean correct scores achieved by each group for $\mathrm{NH}$ and $\mathrm{H}$ sets. *Significant difference 
statement:

$$
A_{n}(N H)>A_{n}(H) ;
$$

therefore, the comparison group of subjects with RVA's of 6 years, 1 month, to 6 years, 10 months, did use a phonological code for immediate recall of visual stimuli.

The difference in performance between the $\mathrm{NH}$ and the $\mathrm{H}$ sets of words was not significant for any other group. The following statement can, therefore, be made:

$$
A_{m r}(N H)=A_{m r}(H) ; B_{n}(N H)=B_{n}(H) ; B_{m r}(N H)=B_{m r}(H) ;
$$

therefore, the experimental group of subjects with RVA's of 6 years, 1 month, to 6 years, 10 months, the comparison group with RVA's of 8 years, 1 month, to 10 years, 10 months, and the experimental group with RVA's of 8 years, 1 month, to 10 years, 10 months, did not show preferential use of a phonological recoding strategy for immediate recall of visual stimuli.

\section{Inter-Group Comparisons}

Mean correct scores achieved by the experimental and comparison groups for the $\mathrm{H}$ and $\mathrm{NH}$ conditions are shown in Figure 2. The performance on both $\mathrm{NH}$ and $\mathrm{H}$ sets of words by the $A_{\mathrm{mr}}$ group was not significantly different from that of the $A_{n}$ group. That is, at the 6 years, 1 month, to 6 years, 10 months, RVA leve1, the MR group matched approximately the same number of pictures as the normal group for both sets of words. On the $\mathrm{NH}$ words, however, the $\mathrm{A}_{\mathrm{n}}$ group came extremely close to achieving significantly higher scores than the $A_{\mathrm{mr}}$ group, so the results can be said to show a trend toward a significantly better performance by the comparison group. The approximately equal scores indicate that the two groups may have been using equally efficient mnemonic skills, even though the comparison group was using a phonological code as a learning strategy and the experimental group was not. 


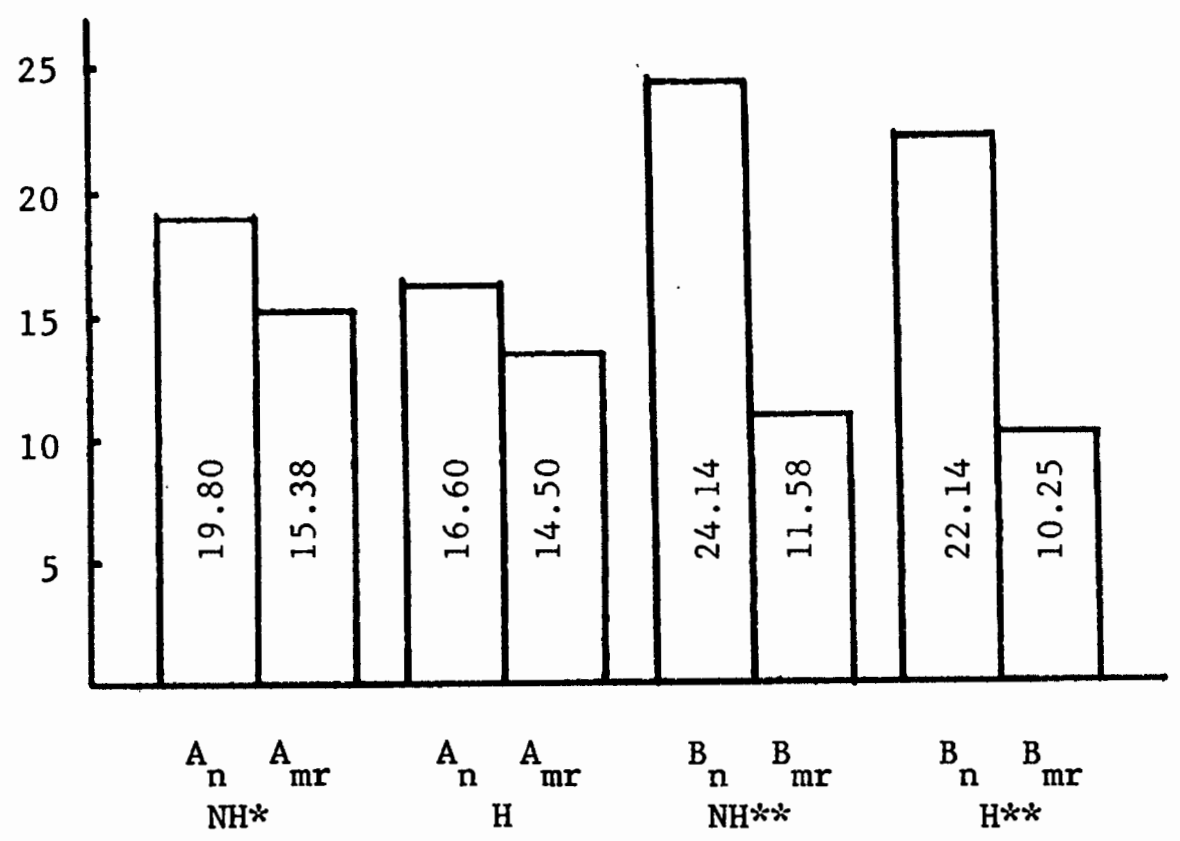

Figure 2. Inter-group comparisons showing mean correct scores achieved by experimental and comparison groups for the $\mathrm{H}$ and $\mathrm{NH}$ sets.

*Trend

**Significant difference

It might be said that qualitatively the responses of the two groups were dissimilar, although quantitatively they were similar. Further, when matching $\mathrm{NH}$ words; the MR group was shown to fall somewhat behind in mnemonic skills. NH words were the focus for judging whether a phonological recoding strategy was used; if subjects performed better on the $\mathrm{NH}$ words, they were assumed to be using a phonological code for recall. Therefore, at this age level the MR group can be said to be slightly delayed in the development of some short-term memory skills, and this delay might be related to the failure to develop a phonological recoding strategy for short-term memory tasks.

The performance on both $\mathrm{NH}$ and $\mathrm{H}$ words by the $\mathrm{B}_{\mathrm{mr}}$ group was 
significantly lower than that of the $B_{n}$ group. That is, at the 8 years, 1 month, to 10 years, 10 months, RVA level, the comparison group matched a significantly larger number of pictures than did the experimental group for both sets of words. The mnemonic skills of the older MR group seemed to have fallen considerably behind those of the comparison group, although neither group showed evidence of preferential use of a phonological recoding strategy. The short-term memory abilities of the comparison group increased with increase in RVA as evidenced by considerably higher mean scores, but the short-term memory abilities of the MR group declined with increase in RVA. Mean scores of the older MR group were lower than mean scores of the older comparison group and both the younger RVA groups. So, not only did the MR group show a decrease in mnemonic abilities in relation to the comparison group, they also showed a deterioration in relation to the performance of the younger MR group. Even though the MR group increased in language age, they fell further behind normal performance in relation to the memory task.

Further, although neither $B_{n}$ nor $B_{m r}$ group showed evidence of use of a phonological recoding strategy, it cannot be assumed that the two groups were using similar tactics to facilitate memory, since their results were so different. Because of the quantitative difference in responses, a qualitative difference is indicated. It seems reasonable to conclude that the phonological code in evidence for the $A_{n}$ group was replaced in the $B_{n}$ group by a strategy or strategies at least as efficient, if not more so, since with increase in RVA the overall level of performance increased substantially in the comparison group. The MR 
group, on the other hand, did not seem to have developed a phonological recoding strategy at the younger age level, nor did they develop one later. In fact, the strategy which was used to stay apace with the comparison group at the younger RVA level was not efficient for the more difficult task.

\section{Correlation of Data}

Studies can be found in the literature both to support and oppose the trends shown by the data. A variety of factors must be considered in explanation of the results gathered from this study.

Institutionalization. Six separate studies were reviewed in relation to the differences in overall performances between the $B_{n}$ and $\mathrm{B}_{\mathrm{mr}}$ groups. Although none of the studies reviewed paralleled retarded and normal subjects at different RVA levels at once, each used picture stimuli in paired-associate learning tasks, with subjects matched for MA (equivalent to RVA used in this study). One study (Cantor and Ryan, 1962) showed similar memory performance at the six-to-seven-age level, and one (Iscoe and Semler, 1964) showed superior performance by the normal group at the same age level. At the eight-to-eleven-age leve1, two studies showed similar memory performance for the two groups (Girardeau and Ellis, 1964; Heckman, 1966), and two showed superior performance by the normal group at that age level (Rieber, 1964; Jensen, 1965). Interestingly, two of the studies reporting superiority of normal subjects used institutionalized mentally retarded individuals as subjects, whereas most of the studies reporting equal rates of learning used non-institutionalized subjects. It seems that the fact of being institutionalized rather than being retarded may have been one 
factor responsible for deficient performance. In the present study five experimental group subjects were residents of a private, full-care facility, and the remainder all attended public schools and lived at home. Of these five, three were in the $B_{m r}$ group and two in the $A_{m r}$ group. All "institutionalized" subjects received total scores below the mean for their groups (see Table III). The possibility is, therefore, present that the factor of institutionalization affected results to some degree. However, both A and B experimental groups contained institutionalized individuals in the same proportion ( $3 / 12$ and $2 / 8)$;

\section{TABLE III}

RVA SCORES AND TOTAL CORRECT SCORES FOR A AND $\mathrm{B}_{\mathrm{mr}}$ "INSTITUTIONALIZED" GROUP MEMBERS, m $^{\mathrm{m}} \mathrm{S}$ COMPARED WITH GROUP MEAN SCORES

\begin{tabular}{lccccc}
\hline \hline Subject & RVA & $\begin{array}{c}\text { Tnst. } \\
\text { Total }\end{array}$ & $\begin{array}{c}\text { Non-Inst. } \\
\text { Group } \\
\text { Mean } \\
\text { Mean }\end{array}$ & $\begin{array}{r}\text { Total } \\
\text { Group } \\
\text { Mean }\end{array}$ \\
\hline${ }_{\mathrm{mr}}{ }^{(1)}$ & $6-6$ & 21.0 & & & \\
$\mathrm{~A}_{\mathrm{mr}}{ }^{(2)}$ & $6-6$ & 19.0 & 20.0 & 33.2 & 29.9 \\
$\mathrm{~B}_{\mathrm{mr}}{ }^{(1)}$ & $9-5$ & 14.0 & & & \\
$\mathrm{~B}_{\mathrm{mr}}{ }^{(2)}$ & $10-0$ & 12.0 & 11.0 & 25.0 & 21.4 \\
$\mathrm{~B}_{\mathrm{mr}}{ }^{(3)}$ & $10-5$ & 11.0 & & & \\
\hline
\end{tabular}

and although the $B$ groups showed differences in ability between the experimental and comparison groups, the A groups did not. Even with the institutionalized members, the $A_{m r}$ group received scores similar to 
those of the $A_{n}$ group. In addition, the "institution" in question was a private residential facility, we11-equipped and designed, and the residents could not be considered to have been deprived of any language or learning stimulation because of their residency there. The probability that the factor of institutionalization created a significant difference in scores between groups may be considered minimal, although the possibility must be taken into consideration.

Presentation Rate. Another factor which may have affected overall performance is rate of presentation. In the present study approximately eight seconds elapsed between the time the last test picture was displayed and the last test picture was turned over. The subject was allowed approximately five seconds to observe the pictures in sequential order. Studies by Ring (1965), Baumeister, Hawkins, and Davis (1968), and Heckman (1966) indicated that presentation rate affects learning of paired-associate tasks by normal and mentally retarded subjects in different ways. For normal subjects, there was minimal effect on performance when either the anticipation interval or the stimulus/response exposure interval was varied. For the MR subjects, lengthening of these intervals apparently facilitated paired-associate learning. It is possible that the difference between performances by the experimental and comparison groups in the present study may have been decreased had the anticipation interval been increased. The rehearsal associated with phonological recoding would have been facilitated also by a longer anticipation interval, and may have provided an opportunity for rehearsal to the MR subjects not provided them by the shorter time lapse. The discrepancy between the $B_{n}$ and $B_{m r}$ performance 
scores may have thus decreased, lending more credence to the quantitative difference argument, and providing more evidence that the MR population applied learning strategies in the same manner as the normal population but at a slower rate.

Short-Term Memory. Although there is disagreement as to the connection, if any, between short-term memory and long-term learning, it has been suggested that the two operations are performed by the same system (Wickelgren, 1965) and that experimental evidence concerning short-term memory may have valuable implications for long-term memory and long-term learning.

Wickelgren (1965) contended, "There is very good agreement that STM is being studied when the list is presented once at a rate of less than two seconds per item and retention is assessed after less than thirty seconds. . ." Even so, there is not total agreement as to what specific time intervals represent actual storage of information in short-term memory or, indeed, whether a distinction can be made between STM, a more immediate recall system which may not require utilization of the entire process, and long-term memory. Until these issues are satisfactorily settled, no concise judgment can be made concerning the memory function tested. Slight differences in timing may make a great deal of difference in the memory process tested, or none at all. For the present study the definition of short-term memory was based on Wickelgren's statement of essential agreement; however, difference in opinion regarding the short-term memory process must be recognized and the implications considered.

Non-Specific Transfer Deficiency. It was further observed in the 
present study that, on the average, the chronologically older subjects made the smallest number of correct matches of any group. In fact, the oldest subjects (over twenty years of age) received three of the four lowest overall scores (see Table IV).

TABLE IV

SCORES FOR MEMBERS OF $B_{\mathrm{mr}}$ GROUP OVER TWENTY YEARS OF AGE

\begin{tabular}{lccccr}
\hline & & & $\begin{array}{c}\text { Mean } \\
\text { for } \\
\text { Oldest }\end{array}$ & $\begin{array}{r}\text { Mean } \\
\text { for } \\
\text { Youngest }\end{array}$ & $\begin{array}{r}\text { Total } \\
\text { Group } \\
\text { Mean }\end{array}$ \\
\hline $24-2$ & $10-0$ & 12.0 & & & 21.4 \\
$24-8$ & $10-5$ & 11.0 & 12.3 & 25.0 & \\
$42-7$ & $9-5$ & 14.0 & & & \\
\hline
\end{tabular}

Since the oldest subjects also were those subjects living in the fu11-care residential facility, there is the possibility that the factors of age and institutionalization both present in the same group compounded the effects. However, the chronologically oldest subjects did not receive the lowest RVA scores of the group. The fact that the RVA scores for these three subjects were at or above the mean for the group minimizes the possibility that they performed differently because they exhibited a significantly lower ability level due to either institutionalization or age.

It might ordinarily be expected that increase in chronological age, with correspondent increase in life experience, would facilitate rather than hinder performance on a task requiring verbal or memory 
skills. Mental retardation notwithstanding, chronologically older subjects would be expected to have had more practice in memory skills by virtue of having met with more situations requiring mnemonic abilities. Yet a considerably larger gap existed between $B_{m r}$ and $B_{n}$ scores than between $A_{m r}$ and $A_{n}$ scores. Goulet (1968) presented a possible explanation by distinguishing between two types of transfer of learning, specific and non-specific. Non-specific transfer results from practice on earlier tasks and does not require similarity between the original and the new learning. This phenomenon has been called "learning how to learn" or "learning set" (Hamilton, 1950; Harlow, 1949). Specific transfer, on the other hand, is dependent upon the similarity or relationship between new learning tasks and earlier learning. Goulet suggested that the effects owing to chronological age (CA) are those related to specific transfer. Therefore, although the older MR subjects might have benefited had the task been similar to a specific task they had learned before, they were not able to apply a learning strategy to a new task.

This conclusion is corroborated by the general trends shown in the primary results of this study. The intra-group comparisons performed on the data implied a failure on the part of the MR group to develop an efficient learning strategy for use with the more difficult task performed by the eight-to-eleven-year RVA group. The inter-group comparisons added emphasis to the implication by demonstrating a greater difference between experimental and comparison group scores as RVA advanced. Some strategies may have been developed by the younger MR population for use in simple memory tasks, since they were able to 
achieve scores similar to those achieved by the younger comparison group. However, if strategies were developed, they did not appear to be the same as those used by the normal group of the same RVA, nor were they developed sufficiently by RVA eight-to-eleven years to be applicable to more difficult tasks. By the eight-to-eleven RVA level, performance of the comparison group was shown to be so superior to that of the MR group that the t-value could be carried to the .0005 level of significance.

The explanation for the differences between groups observed in the present study might be that the comparison group had learned to diversify learning strategies by the eight-to-eleven RVA level, and the MR subjects had not. That is, the comparison subjects had learned to apply a diverse repertoire of learning strategies to the task at hand. The technique of applying a strategy to a learning task might have been developed in the normal subjects to the point that a number of strategies could be successfully applied. The diversity would account for the lack of evidence that the group preferred a phonological recoding strategy at that level, as might have been expected from Conrad's (1971) data. Furthermore, although the normal subjects eventually did not show a preference for a phonological code, the basis of the later "learning set" appeared to lie in the earlier application of a phonological recoding strategy to the learning task. Since the group showing evidence of use of a phonological code $\left(A_{n}\right)$ increased total correct scores at a higher RVA $\left(B_{n}\right)$, and the group showing no evidence of use of a phonological recoding strategy $\left(\mathrm{A}_{\mathrm{mr}}\right)$ decreased total correct scores at a higher RVA $\left(B_{m r}\right)$, it might be postulated that the use of a 
phonological recoding strategy was somehow essential to the later suc- . cess in a short-term memory task.

The MR subjects seemed to have applied learning strategies at the younger RVA leve1, but either never developed a basis from which to diversify or only developed strategies to a certain level which became insufficient for more advanced learning. The application of a learning strategy to a new task has been termed "non-specific transfer"; the failure on the part of the MR subjects in this study to develop and apply a learning strategy supports the existence of a "non-specific transfer deficiency" in these subjects. Clinically, this type of deficiency in mentally retarded individuals is widely recognized. In the words of Goldstein (1975), ". . . the name of the game is . . generalization."

Quantitative vs. Qualitative. The data reviewed above imply a qualitative difference in response by the MR and normal groups. Qualitatively different responses may be identified as those which showed use of different types of learning strategies, so that the essence or quality of the response differed from group to group (Yoder and Miller, 1972). This type of difference was evident in the data which showed that the $A_{n}$ group used a phonological recoding strategy and the $A_{m r}$ group did not. In the literature, Jordan (1967), Semmel, Lefson, and Sitko (1966), and Semmel and Herzog (1966) also found qualitative differences between MR and normal groups in the application of linguistic knowledge to language-dependent tasks.

Quantitative differences between experimental and comparison groups also were observed. Quantitatively different responses may be 
identified as those which differ from each other in terms of total number correct, and which would indicate that the process of language development is the same for the MR individual as it is for the normal individual, except that the MR child takes longer to master the skills involved (Yoder and Miller, 1972). This type of difference was evident in the data which yielded significantly higher scores by the $B_{n}$ group than by the $\mathrm{B}_{\mathrm{mr}}$ group. Lenneberg, Nichols, and Rosenberger (1964), Lovell and Dixon (1967), and Fraser, Bellugi, and Brown (1963) present evidence in support of quantitative differences between MR and normal populations.

Had the differences in responses between the two groups been strictly quantitative, it might have been assumed that both groups used the same strategies, but one group lagged behind the other in the development of the applied skills. In this case the null hypothesis would have been supported. Had the differences been strictly qualitative, it might have been assumed that the MR subjects did not and never would develop the same strategies as the normal group because their approach to learning was different. In this case the null hypothesis would have had no support.

But the present study indicated that differences between normal and MR groups in short-term memory skills and in application of learning strategies were not identifiable as strictly qualitative or strictly quantitative. As Yoder and Miller (1972) suggested, mental retardation itself is a general behavioral classification into which children with intellectual deficits of varied character are placed. Present data support that contention, and the clinician must keep it 
in mind when creating language programs suited to individual needs. Discrepancies between the Present Study and Conrad's Data. A number of important differences can be found in the results obtained in the present study and those obtained in the research upon which this study was based (Conrad, 1971). Conrad's essential results (Figure 3a) reveal that normal subjects use a phonological recoding strategy for a short-term memory task with increasing preference as MA increases until, at MA eight to eleven years, the phonological code is used almost exclusively. Present data (Figure $3 b$ ) show no such trend; in fact, the preference for a phonological code shown by the lower RVA comparison group disappears altogether in the older RVA group. Second$1 y$, Conrad considered results from children with MA's of eight to eleven years homogeneous enough to include them in the same group for purposes of analysis. The present study showed a considerable difference in performance between the lowest and the highest RVA subjects of the $B_{n}$ group. The RVA 8 years, 1 month, subject (lowest) received a total correct score of $25 / 80$; the RVA 10 years, 10 months, subject (highest) received a total correct score of $71 / 80$. The mean score for the 8 years, 1 month, to 8 years, 11 months, RVA level was 36.8 ; the mean score for the 10 years, 0 months, to 10 years, 10 months, RVA level was 59.5. These scores represent enough difference to suggest considerable growth within the eight-to-eleven-year RVA range, indicating a need to consider each age level separately when exploring a developmental pattern.

Regarding the lack of homogeneity in the eight-to-eleven-year RVA comparison group, it may be seen that had each age level from eight to 


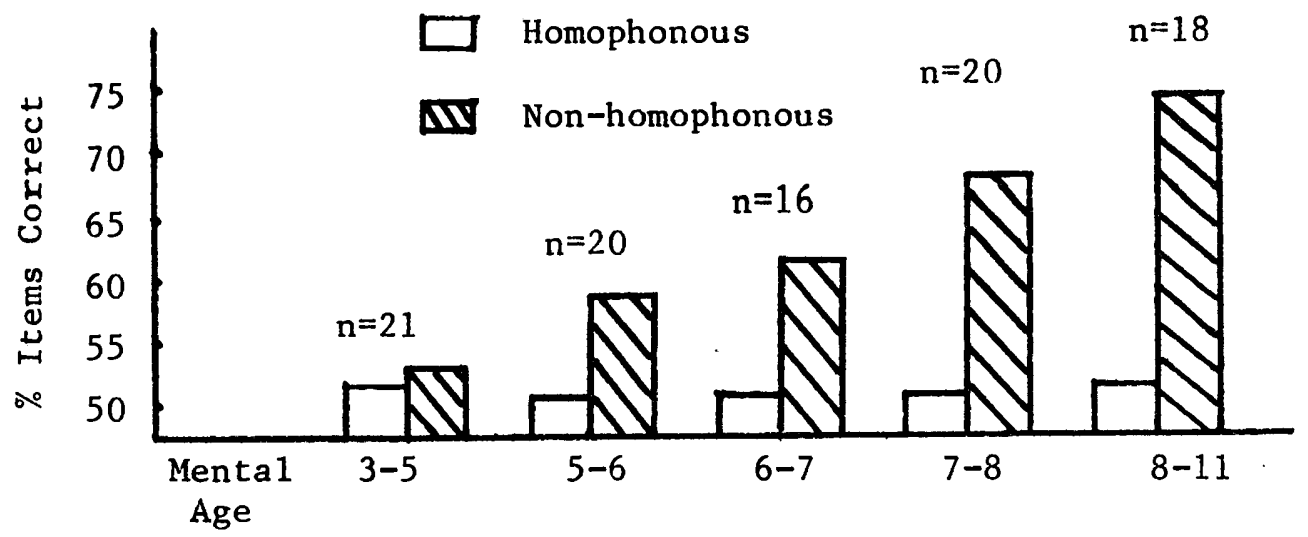

Figure 3a. Effect on recal1 as a function of Mental Age when names of items sound alike or unlike (Conrad, 1971).

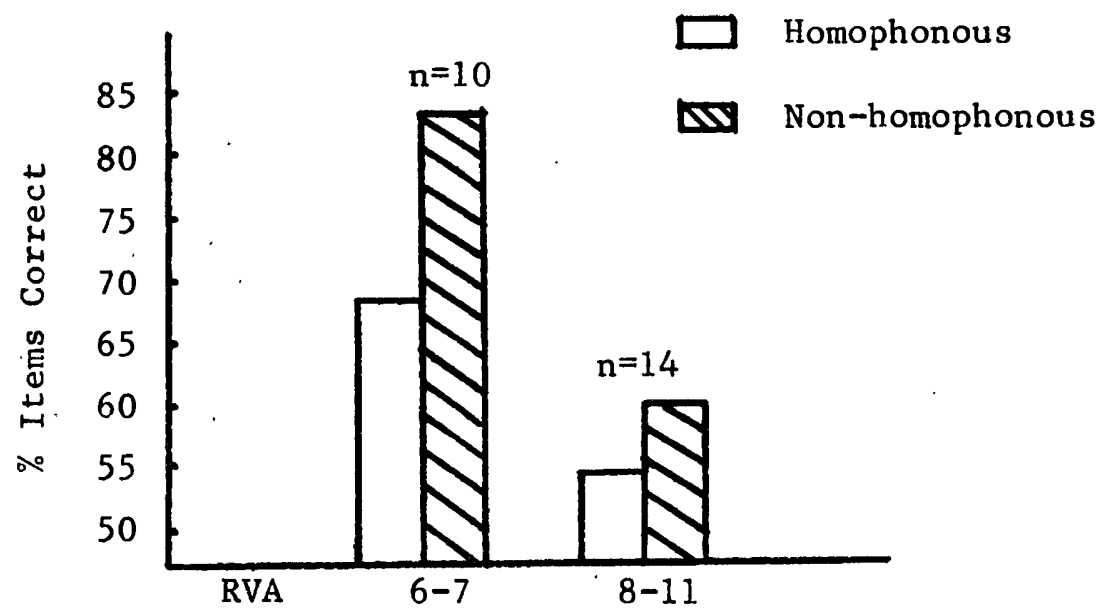

Figure 3b. Effect on recall as a function of RVA when names of items sound alike or unlike ( $A_{n}$ and $B_{n}$ groups), from the present study. 
eleven years RVA been considered separately, the gap between the performances of the $B_{n}$ and $B_{m r}$ groups would only have widened, underscoring the implications of the results already observed. Figure 4 shows that scores of the 10 years, 0 months, to 10 years, 10 months, RVA level for the $B_{n}$ group were even higher in relation to the 10 years, 0 months, to 10 years, 10 months, $\mathrm{B}_{\mathrm{mr}}$ group than were the scores of the entire 8-to-11-year group.

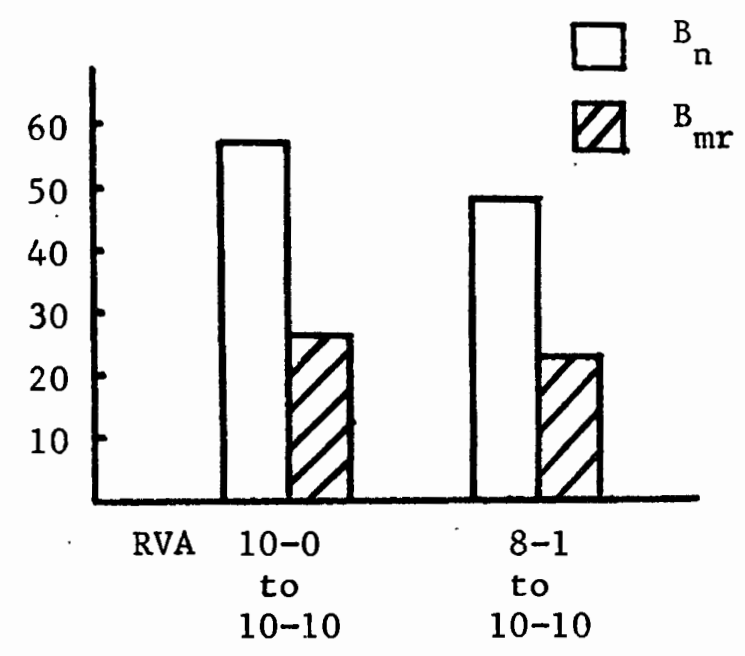

Figure 4. Mean scores for highest RVA level in B groups compared with mean scores for entire $B$ group.

Neither does there seem to be a greater preference for a phonological code in the highest RVA level group than in the entire B group. Table $\mathrm{V}$ shows that none of the groups did significantly better on $\mathrm{NH}$ words than on $\mathrm{H}$ words.

The 10 years, 0 months, to 10 years, 10 months, group contains only four members in the $B_{m r}$ condition, and six members in the $B_{n}$ condition, so the information received from their scores cannot be considered representative of the population. However, this limited information indicates that the comparison of the 10 years, 0 months, to 
10 years, 10 months, RVA groups would not have yielded significantly different results, even though the scores of the 10 years, 0 months, to 10 years, 10 months, groups were different from the scores of the 8 years, 1 month, to 10 years, 10 months, group as a whole.

TABLE V

MEAN SCORES FOR THE HIGHEST RVA LEVEL COMPARISON GROUP AND THE ENTIRE

GROUP, ON NH AND H WORDS

\begin{tabular}{crr}
\hline Group & $\mathrm{NH}$ & $\mathrm{H}$ \\
\hline $\mathrm{B}$ & & \\
\hline $\mathrm{B}_{\mathrm{mr}}(10-0$ to $10-10)$ & 32.8 & 26.7 \\
$\mathrm{~B}_{\mathrm{B}}^{\mathrm{n}(8-1 \text { to } 10-10)}$ & 12.5 & 9.2 \\
${ }_{\mathrm{mr}}(8-1$ to $10-10)$ & 24.1 & 11.6 \\
\hline
\end{tabular}

A number of other differences between the two studies must be taken into account in regard to the observed discrepancies.

1. Setting: Each subject in the present study was tested individually in a quiet room located in the facility through which he was contacted, usually the public school. Therefore, the testing environment differed somewhat from subject to subject, although differences were judged minimal. Nevertheless, it is possible that Conrad's study was carried out in a clinical setting unfamiliar to the subjects and amenable to more controlled conditions, and this discrepancy may have affected results.

2. Words Used: A number of the homophonous words which Conrad used were judged to be less familiar to American children than to the 
British children of Conrad's study; therefore, "can," "fan," and "pan" were substituted for Conrad's "mat," "bag," and "tap." In an effort to avoid consonant clusters in the non-homophonous words, as well as avoid repetition of any sound, "nail," "dog," "house," "coat," "bird," and "leaf" were used instead of "girl," "bus," "train," "horse," "clock," and "hand." These changes may have changed the difficulty of the task for one group or the other, or for both.

3. Examiner: The possibility of examiner inconsistency or differences in levels of rapport established by this examiner and by the examiners, in Conrad's study must be taken into consideration.

4. Factor Held Constant: Conrad designed his study so that each subject was presented the number of pictures necessary to obtain a 50 percent correct response ratio on the homophonous set of words. Recall of the $\mathrm{H}$ pictures was held constant, and the data analyzed were the number of $\mathrm{NH}$ words correctly recalled. Since the number of $\mathrm{H}$ words was held at chance level, it was unlikely that the $\mathrm{NH}$ scores would fall below; in fact, they did not. A significantly higher score on the NH words represented a phonological code preference, and equivalent scores represented failure to show evidence of a phonological code preference. In the present study, the number of cards presented was held constant, and the data analyzed were the number of $\mathrm{NH}$ words correctly recalled compared with the number of $\mathrm{H}$ words correctly recalled. Since the control in the experiment was the normative data produced by the comparison group, it was not necessary or expedient to use the H words as a control. In this case it was possible for the score on the NH words to fall above or below the $\mathrm{H}$ score. The results, however, were 
interpreted in essentially the same manner; a significantly higher score on the $\mathrm{NH}$ words represented a phonological code preference; equivalent or lower NH scores represented failure to show evidence of phonological code preference. This difference in experimental design might have contributed to test result difference, as might any structural difference between the two tests. 
CHAPTER V

SUMMARY AND IMPLICATIONS

\section{SUMMARY}

Research has indicated that language, in the form of the "inner language" described by Vygotsky (1962), plays a major mediational role in learning. Researchers have described a "phonological" recoding strategy which seems to develop in normal children with the acquisition of receptive and expressive language skills (Conrad, 1971; Sperling, 1963; Locke and Kutz, 1975; Wickelgren, 1965; Hintzman, 1967). However, the mentally retarded population has been described as having a "mediational deficiency" (Luria, 1961; Gallagher, 1969; Kendler and Kendler, 1962), although results have not been conclusive.

The purpose of the present study was to investigate the presence or absence of a phonological recoding strategy in the mentally retarded population by using a memory matching exercise with visual stimuli. Pictures of common objects were divided into eight pictures with names that sound alike (homophonous) and eight with names that do not sound alike (non-homophonous). The nu1l hypothesis tested was:

No statistically significant difference will be found between mentally retarded and normal subjects in the development and use of a phonological recoding strategy for a short-term memory task, when the subjects are matched for receptive. vocabulary age.

The younger Receptive Vocabulary Age (RVA) comparison group ( $A_{n}$ ) subjects were the only group that showed evidence of use of a phono- 
logical code; therefore, the null hypothesis was rejected. The younger RVA experimental group $\left(A_{m r}\right)$ performed as well as the $A_{n}$ group, but did not use a phonological code. The older RVA comparison group $\left(B_{n}\right)$ performed better than all the other groups in accordance with their increased language capacity, but they did not exclusively use a phonological code. The older RVA experimental group ( ${ }_{\mathrm{mr}}$ ) made fewer correct matches, on the average, than all the other groups, and did not use a phonological code.

These results did not conform to the research upon which the present study was based. In explanation, a number of factors must be considered: setting, words used, examiner, and factor held constant. Other factors which may have affected results are: institutionalization, rate of presentation, and the definition of short-term memory that was used.

After all these factors have been considered, it may be postulated that the difference in scores between groups may have been due to the fact that the mentally retarded group never acquired a "learning set," or never "learned how to learn." This resulted in increasingly deficient performances on learning tasks as the tasks became more difficult. It also may be postulated that the "learning set" related to short-term memory tasks involves as its basis the use of a phonological recoding strategy, which may predominate in normal children at lower levels of performance and then, as the individual becomes more competent, recede into a more diverse repertoire of learning strategies. This postulation would take Vygotsky one step further. The process of diversification of learning strategies was 
observed in the comparison subjects but not in the experimental subjects, indicating a qualitative difference in the manner in which the two groups approach a learning task. A quantitative difference in their overall performances also was observed between the two groups.

\section{IMPLICATIONS}

\section{Clinica1 Implications}

Results of this study imply that language management of mildly mentally retarded individuals cannot be based entirely on a normal developmental paradigm. The mentally retarded individuals in this study not only performed more poorly than the normal subjects, but they also seemed to approach the memory task in a completely different manner. This difference seemed to stem from a deficiency in the ability to generalize a "learning set" to a new task, as well as a general deficiency in the development of language skills. It seems reasonable to conclude that any educational program for a mentally retarded individual will require a strong basis in learning skills, since, as data from this study imply, the mentally retarded child will not develop these skills spontaneously as will the average child. Indications are that verbal mediational skills can be taught effectively to mentally retarded individuals. Goulet (1968) cited a considerable number of studies which demonstrated that MR subjects utilized verbal mediators for a variety of learning tasks when specifically instructed to do so. Since the comparison children in this study seemed to use a phonological recoding strategy before they learned to apply diverse strategies, that is, at the 6 years, 1 month, to 6 years, 10 months, 
RVA level, it may be beneficial to teach that particular strategy to the MR child first. A program might easily be developed from which the child would learn to recode various types of stimuli into a languagebased code for retention. The effectiveness of such a program, however, would depend on the child's language development and so might necessarily run concurrent with or subsequent to an intensive language program for expressive and receptive language skills. Vygotsky (1962) indicated that in normal children language skills used in a communicative capacity are developed before the use of inner language in a mediational capacity.

The requirement that the child have good receptive and expressive language skills before embarking on a program for learning skills underscores the vital importance of a language management program for MR children. Ideally, such a program should begin as early as possible, with infant stimulation through an enriched environment. Continued training should be based on instruction in generalization skills, as "non-specific transfer deficiency" seems to be a particular problem for mentally retarded individuals. Clinicians have long grappled with the problem of transfer or generalization of specific skills; dealing with the mentally retarded population calls for methods to instruct transfer of the skill of learning to learn. There seem to be no conclusive answers, nor are there foolproof methods. The need for extensive research, both in the laboratory and in the clinic room, is evident.

\section{Implications for Research}

Research could be conducted in the clinic room by administration of various types of educational programs and comparison of results, to 
discover which type of approach to learning, if any, is more effective for mentally retarded children. A program might be devised specifically to teach a phonological recoding strategy, with follow-up studies to determine if use of a phonological code represents the beginning of a "learning set" for MR children as it seems to for normal children.

In the laboratory, studies might be devised to discover what learning strategies, if any, the younger MR subjects were using which resulted in a performance equivalent to that of the normal children using a phonological code. If a preference for another type of learning strategy is found, an intensive program might be devised to teach more efficient and flexible use. If no preferred strategy is found, it might be important to discover whether teaching one specific strategy will lead to generalization to more difficult learning tasks.

The present study might be duplicated, using more subjects at each RVA level and differently controlled conditions, in an attempt to obtain results more closely resembling those obtained for normal children in Conrad's often-cited 1971 study. It may be beneficial to investigate only one RVA level at a time, comparing normal and MR performances across one-year RVA differences. In this manner a more specific developmental pattern may emerge. More accurate results also may be obtained if longer times were allowed for rehearsal, or if rehearsal times were varied in controlled conditions to discover if a difference in stimulus/response exposure times makes a difference in MR performance.

In order to uncover similarities between the MR population and the learning disordered population, who also give qualitatively differ- 
ent responses to learning tasks, this study might be repeated using three groups: normal, MR, and learning disabled.

Although extensive research has been done in the area of mental retardation, many questions are unanswered, and problems unsolved. Results of studies comparing MR subjects with other MR subjects, as we11 as those comparing MR subjects with normal subjects, have been inconclusive and even contradictory. No one study, therefore, should be taken at face value as an accurate description of the behavior of mentally retarded individuals. The present study is a case in point, since the results contradicted the results of the study upon which this study was based. The data could not be aligned with any single previous conclusion, but agreed at various points with a number of conclusions from opposing schools of thought. When working with the mentally retarded child, both clinician and researcher must be familiar with current attitudes and approaches to management, and must be knowledgeable enough to be selective in applying theory to practice. 
$\underline{\mathrm{S}} \underline{\mathrm{E}} \underline{\mathrm{L}} \underline{\mathrm{E}} \underline{\mathrm{C}} \underline{\mathrm{T}} \underline{\mathrm{E}} \underline{\mathrm{D}}$

B I B $\underline{L} I \underline{O} G \underline{R}$ A P $\underline{\mathrm{H}} \underline{\mathrm{Y}}$ 
BALLA, D., and ZIGLER, E., Discrimination and switching learning in normal, familial retarded, and organic retarded children. J. Experimenta1 Psychology, 69, 664-669 (1973).

BAUME ISTER, A. A., HAWKINS, W. F., and DAVIS, P. A., Stimulus-response durations in paired-associates learning of normals and retardates. American J. Mental Deficiency, 70, 580-584 (1966).

BERKSON, G., and CANTOR, G. N., A study of mediation in mentally retarded and normal school children. J. Educational Psychology, $51,82-86$ (1960).

BLOOMF IELD, L., Language. New York: Holt, Rinehart \& Winston (1933).

BORKOWSKI, J. G., and JOHNSON, L. O., Mediation and the pairedassociate learning of normals and retardates. American J. Menta1 Deficiency, 72, 610-613 (1968).

BORKOWSKI, J. G., and WANSCHURA, P. B., Mediational processes in the retarded. In N. R. Ellis (Ed.), International Review of Research in Mental Retardation, Vo1. 7. New York: Academic Press, Inc. (1974).

BRIMER, M. A., and DUNN, L. M., English Picture Vocabulary Test. England: Educational Evaluation Enterprises (1962).

CANTOR, G. N., and RYAN, T. J., Retention of verbal paired-associates in normals and retardates. American J. Mental Deficiency, 66, 861-865 (1962).

CHERRY, L., and LEWIS, M., Mothers and 2-year-olds: A study of sexdifferentiated aspects of verbal interaction. Developmental Psychology, 12(4), 278-297 (1976).

CHENG, C., Different roles of acoustic and articulatory information in short-term memory: J. Experimental Psychology, 4, 614-618 (1974).

COLE, R., COLTHEART, M., and ALLARD, F., Memory of a speaker's voice: Reaction time to same- or different-voiced letters. Quarterly J. Experimenta1 P'sychology, 26, 1-7 (1974).

CONRAD, R., An association between memory errors and errors due to acoustic masking of speech. Nature, 193, 1314 (1962). 
CONRAD, R., Acoustic confusions and memory span for words. Nature, $197,1029-1030$ (1963).

CONRAD, R., Acoustic confusions in immediate memory. British J. Psychology, 55, 75-84 (1964).

CONRAD, R., The chronology of the development of covert speech in children. Developmenta1 Psychology, 5, 398-405 (1971).

CONRAD, R., Short-term memory in the deaf: A test for speech coding. British J. Psychology, 63, 173-180 (1972).

CONRAD, R., FREEMAN, P. R., and HULL, A. J., Acoustic factors versus language factors in short-term memory. Psychonomic Science, 3, 57-58 (1965).

CONRAD, R., and RUSH, M. L., On the nature of short-term memory encoding by the deaf. J. Speech and Hearing Disorders, 30, 336 (1965).

CORCORAN, D. W., An acoustic factor in letter cancellation. Nature, 210,658 (1966).

DALE, P. S., Language Development. Hinsdale, I11.: Dryden Press (1972).

DUNN, L. M., Peabody Picture Vocabulary Test. Circle Pines; Minn.: American Guidance Service (1959).

ELLIS, N. R., International Review of Research in Mental Retardation, Vo1. 4. New York: Academic Press (1970).

ELLIS, N. R., International Review of Research in Menta1 Retardation, Vol. 7. New York: Academic Press (1974).

ESTES, W. K., An associative basis for coding and organization in memory. In A. W. Melton and E. Martin (Eds.), Coding Processes in Human Memory. Washington, D. C.: V. H. Winston \& Sons (1972).

FLAVELL, J. H., BEACH, D. R., and CHINSKY, J. M., Spontaneous verba1 rehearsal in a memory task as a function of age. Child Development, 37, 283-299 (1966).

FRASER, C., Mothers' speech to children of four different ages. J. Psychological Research, 4(1), 9-16 (1975).

FRASER, C., BELLUGI, U.,, and BROWN, R., Control of grammar in imitation comprehension and production. J. Verbal Learning and Verbal Behavior, 2, 21-135 (1963).

GALLAGHER, J. W., Mediation as a function of associative chains in normal and retarded children. American J. Mental Deficiency, 73, 886-889 (1969). 
GIRARDEAU, F. L., and ELLIS, N. R., Rote verbal learning by normal and mentally retarded children. American J. Mental Deficiency, 68, 525-532 (1964).

GLADIS, M., and BRAUN, J. W., Age differences and retroaction as a function of intertask response similarity. J. Experimental Psychology, 55, 25-30 (1958).

GLANZER, M., and CLARK, W., The verbal-loop hypothesis: Binary numbers. J. Verba1 Learning and Verbal Behavior, 2, 301-309 (1963).

GLASSMAN, W. E., Subvocal activity and acoustic confusion in short-term memory. J. Experimental Psychology, 96, 164-169 (1972).

GOLDSTEIN, H., Importance of social learning. In J. M. Kauffman and J. S. Payne (Eds.), Mental Retardation. Columbus, Ohio: Charles E. Merrill Pub1. (1975).

GOULET, L. R., Verbal learning and memory research. In N. R. E11is (Ed.), International Review of Research in Mental Retardation, Vo1. 3. New York: Academic Press (1968).

GROSSMAN, J. J., (Ed.), Manual of Terminology and Classification in Mental Retardation. American Association on Mental Deficiency Special Publication, Series No. 2 (1973).

HAMILTON, C. E., The relationship between length of interval separating two learning tasks and performance on the second task. J. Experimental Psychology, 40, 613-621 (1950).

HARLOW, H. F., The formation of learning sets. Psychological Review, $56,51-65$ (1949).

HEBER, R. F., A manual on terminology and classification in mental retardation. Monograph Supp., American J. Mental Deficiency, 64 (1959).

HEBER, R. F., A manual on terminology and classification in mental retardation (Rev. ed.), Monograph Supp., American J. Mental Deficiency, 64 (1961):

HECKMAN, B., Varied exposure durations in paired-associate learning in normal and retarded children. American J. Mental Deficiency, 70, 709-713 (1966).

HINTZMAN, D. L., Articulatory coding in short-term memory. J. Verbal Learning and Verbal Behavior, 6, 312-316 (1967).

ISCOE, I., and SEMLER, I. J., Paired-associate learning in normal and mentally retarded children as a function of four experimental conditions. J. Comparative and Physiological Psychology, 57, 387-392 (1964). 
JENSEN, A. R., The role of verbal mediation in mental development. J. Genetic Psychology, 118, 39-70 (1971).

JOHNSON, N. F., Chunking: Associative chaining vs . coding. J. Verbal Learning and Verbal Behavior, 8, 725-731 (1969).

JORDAN, T., Language and mental retardation: A review of the literature. In R. L. Schiefelbusch, R. L. Copeland, and J. O. Smith (Eds.), Language and Mental Retardation-Empirical and Conceptual Considerations. New York: Holt, Rinehart \& Winston (1967).

KAUFFMAN, J. M., and PAYNE, J. S. (Eds.), Mental Retardation. Columbus, Ohio: Charles E. Merrill Publ. (1975).

KAUFMAN, H., and IVANOFF, J., Evaluating the mentally retarded with the Peabody Picture Vocabulary Test. American J. Mental Deficiency, 73, 396-398 (1968).

KEENEY, T., CANNIZZO, S., and FLAVELL, J., Spontaneous and induced verbal rehearsal in a recall task. Child Development, 38, 953966 (1967).

KENDLER, H. H., and KENDLER, T. S., Vertical and horizontal processes in problem solving. Psychological Review, 69, 1-16 (1962).

KRESHECK, J. D., and NICOLOS, L. A., A comparison of black and white children's scores on the Peabody Picture Vocabulary Test. Language, Speech, and Hearing Services in the School, 4, 37-40 (1973).

LENNEBERG, E., NICHOLS, I., and ROSENBERGER, E., Primitive stages of language development in Mongolism. Procedures for the Assessment of Respiratory, Nervous, and Mental Disorders, 42, 119-137 (1964).

LIBERMAN, A. M., MATTINGLY, I. G., and TURVEY, M. T., Language codes and memory codes. In A. W. Melton and E. Martin (Eds.), Coding Processes in Human Memory. Washington, D. C.: V. H. Winston \& Sons (1972).

LOCKE, J., Phonetic analysis of pronounceability. Psychological Report, 27, 583 (1970).

LOCKE, J., and KUTZ, K. J., Memory for speech and speech for memory. J. Speech and Hearing Research, 18, 176-191 (1975).

LOCKE, J., and LOCKE, V., Deaf children's phonetic, visual, and dactylic coding in a grapheme recall task. J. Experimental Psychology, 89, 142-146 (1971). 
LOVELL, K., and DIXON, E., The growth of the control of grammar in imitation, comprehension, and production. J. Child Psychology and Psychiatry, 8, 31-39 (1967).

LURIA, A. R., The Role of Speech in the Regulation of Normal and Abnormal Behavior. New York: Liverwright (1961).

MANDLER, G., Organization and memory. In K. W. Spence and J. T. Spence (Eds.), The Psychology of Learning and Motivation, Vo1. 1. New York: Academic Press (1967).

McCARTHY, D., Language development in children. In L. Carmichael (Ed.), Manual of Child Psychology. London: John Wiley \& Sons (1946).

MCCARTHY, J. J., Research on the linguistic problems of the mentally retarded. Mental Retardation Abstracts, 2, 90-96 (1964).

MCGEOCH, J. A., and MCDONALD, W. T., Meaningful relation and retroactive inhibition. American J. Psychology, 43, 579-588 (1931).

MCLEAN, J. E., YODER, D. E., and SCHIEFELBUSCH, R. L., Language Intervention with the Retarded. Baltimore: University Park Press (1972).

MELTON,. A. W., and MARTIN, E., (Eds.), Coding Processes in Human Memory. Washington, D. C.: V. H. Winston \& Sons (1972).

MILGRAM, N. A., and FURTH, H. G., The influence of language on concept attainment in educable retarded children. American J. Mental Deficiency, 67, 733-739 (1963).

MILLER, G. A., The magic number seven, plus or minus two: Some limits on our capacity for processing information. The Psychological Review, 63, 81-97 (1956).

MORTON, J., A functional model for memory. In D. A. Norman (Ed.), Models for Human Memory. New York: Academic Press (1969).

NIHIRA, K., FOSTER, R., SHELLHAAS, M., and LELAND, H., AAMD Adaptive Behavior Scale (1974 revision). Washington, D. C.: American Association on Mental Deficiency (1974).

O'CONNOR, N., and HERMELIN, B., Discrimination and reversal learning in imbeciles. J. Abnormal and Social Psychology, 59, 409-413 (1959).

OSGOOD, C. E., An investigation into the causes of retroactive inhibition. J. Experimenta1 Psychology, 38, 132-154 (1948).

OSGOOD, C. E., The similarity paradox in human learning: A resolution. Psychological Review, 56, 132-143 (1949). 
PENNEY, R. K., SEIM, R., and PETERS, R., The mediational deficiency of mentally retarded children: I. The establishment of retardates' mediational deficiency. American J. Mental Deficiency, 72, 626630 (1968).

PIAGET, J., The Language and Thought of the Child. New York: Meridian (1955).

PIERCE, J. E., Languages and Linguistics. The Hague: Mouton (1975).

REESE, H. W., Verbal Mediation as a function of age level. Psychologica1 Bulletin, 59, 502-509 (1962).

RIEBER, M., Verbal mediation in normal and retarded children. American J. Menta1 Deficiency, 68, 634-641 (1964).

RING, E. M., The effect of anticipation interval on paired-associate learning in normal and retarded children. American J. Mental Deficiency, $70,466-470$ (1965).

RUNDUS, D., Analysis of rehearsal processes in free recall. J. Experimental Psychology, 89, 63-77 (1971).

RUNDUS, D., and ATKINSON, R. C., Rehearsal processes in free recall: A procedure for direct observation: J. Verbal Learning and Verbal Behavior, 9, 99-105 (1970).

SANDERS, D. A., Auditory Perception of Speech. Englewood C1iffs: Prentice-Ha11 (1977).

SCHIEFELBUSCH, R. L., COPELAND, R. H., and SMITH, J. O. (Eds.), Language and Mental Retardation. New York: Holt, Rinehart \& Winston (1967).

SEMMEL, M., and HERZOG, B., The effects of gramnatical form class on the recall of Negro and Caucasian educable retarded children. Studies of Language and Language Behavior, 3, 1-19 (1966).

SEMMEL, M., LEFSON, M., and SITKO, M., Learning and transfer of paradigmatic word association by educable mentally retarded children: A preliminary report. Studies of Language and Language Behavior, $5,343-363(1966)$.

SPERLING, G., A model for visual memory tasks. Human Factors, 5, 1931 (1963).

TEMPLIN, M., Certain Language Skills in Children. Minneapolis: University of Minnesota Press (1957).

VYGOTSKY, L. S., Thought and Language. Cambridge, Mass.: MIT Press (1962). 
WICKELGREN, W. A., Acoustic similarity and retroactive interference in short-term memory. J. Verbal Learning and Verbal Behavior, 4, 53-61 (1965).

WILLIAMS, A. M., MARKS, C. J., and BIALER, I., Validity of the Peabody Picture Vocabulary Test as a measure of hearing vocabulary in mentally retarded and normal children. J. Speech and Hearing Research, 20, 205-211 (1977).

YODER, D. E., and MILLER, J. F., What we may know and what we can do. In J. E. McLean, D. E. Yoder, and R. L. Schiefelbusch (Eds.), Language Intervention with the Retarded. Baltimore: University Park Press (1972).

YOUNG, R. K., Retroactive and proactive effects under varying conditions of response similarity. J. Experimental Psychology, 50, 113-119 (1955).

YOUNISS, J., and FURTH, H., Reaction to a placebo: The mediational deficiency hypothesis. Psychologica1 Bulletin, 60, 499-502 (1963). 
A $\underline{P} \underline{P} \underline{E} \underline{N} \underline{D} \underline{I} \underline{\mathrm{C}} \underline{\mathrm{S}} \underline{\mathrm{S}}$ 


\section{APPENDIX A}

PERMISSION LETTER TO PARENTS

\section{Dear Parents,}

As part of the requirements to obtain a master's degree in Speech and Hearing Sciences from Portland State University, I am conducting a thesis research project. My research is concerned with language development as it relates to learning. I ask your permission for your son or daughter to participate in the study. I have obtained approval from the principal and the Area II Office of Evaluation and Research to conduct this study at your child's school during the month of January, 1978 .

The procedure will have two parts. First, a vocabulary test will be given, and the score will be used to select participants and group them according to their levels of language development. Second, each participant will match pictures of common objects by memory. The pictures have been chosen so that some insight may be gained concerning strategies that people use to remember object names.

No children or teacher names will be recorded or used to report the results. All identifying information will be confidential. Please feel free to call me at home (248-0697) or at Portland State (229-3533) if you have any questions.

I greatly appreciate your assistance. Please sign below and return promptly to your child's teacher.

$$
\begin{aligned}
& \text { Sincerely, } \\
& \text { /s/ Mary Jo Bartels } \\
& \text { Mary Jo Bartels }
\end{aligned}
$$

My son/daughter,

has my permission to participate in the research study described above. 


\title{
APPENDIX B
}

LINE DRAWINGS USED FOR MATCHING TASK

\author{
HOMOPHONOUS WORDS
}

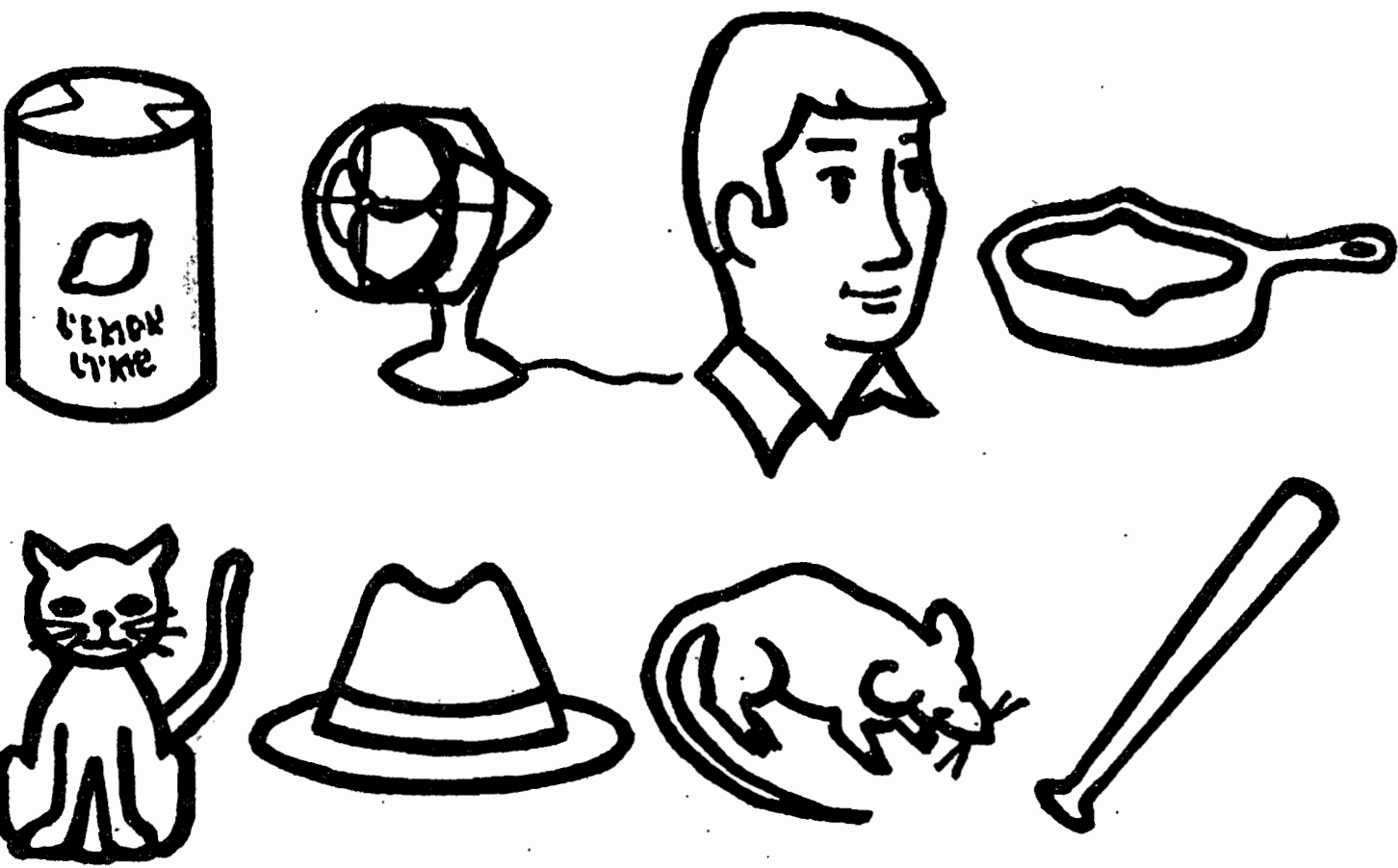


APPENDIX B-Continued

NON-HOMOPHONOUS WORDS

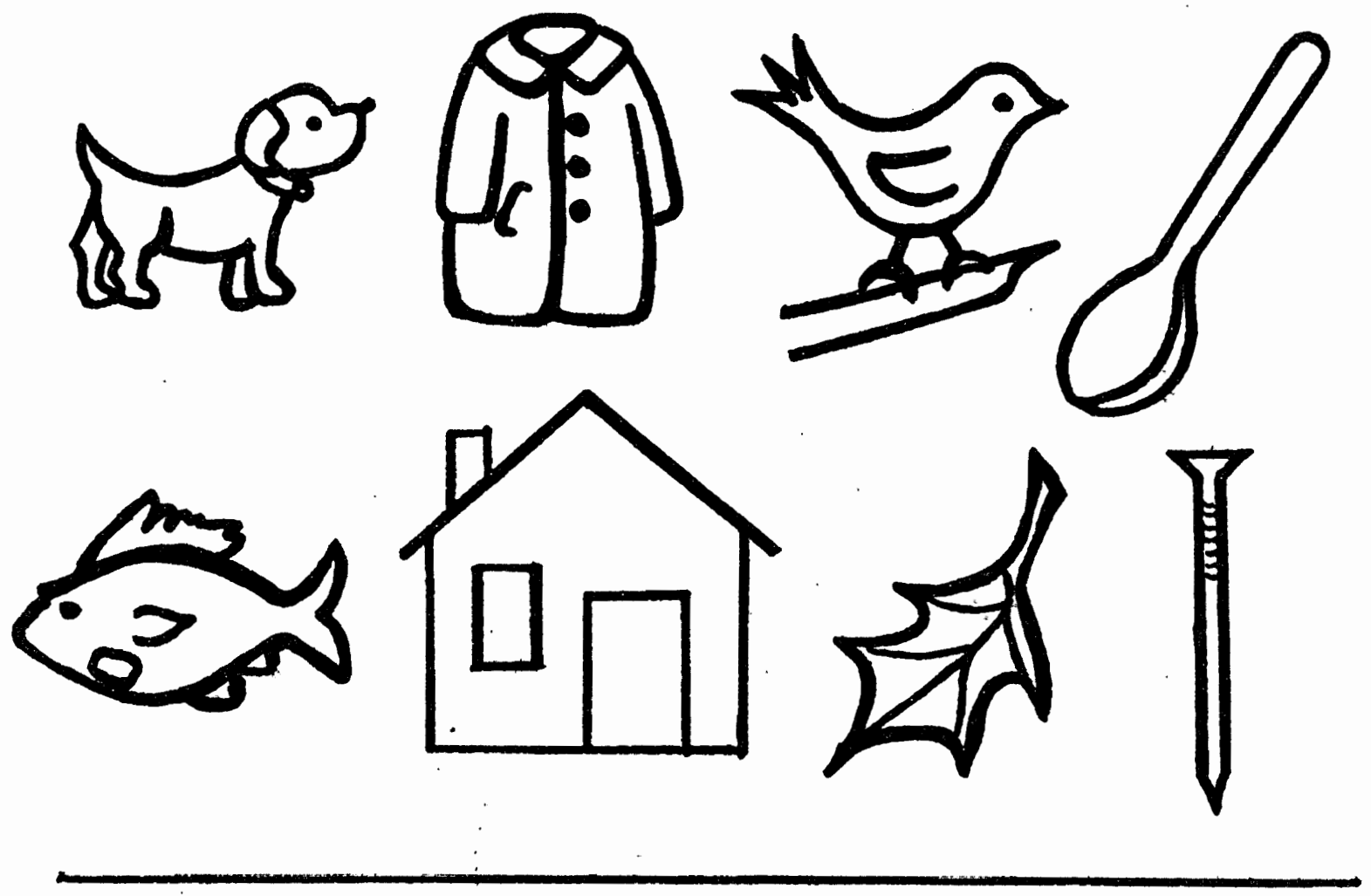




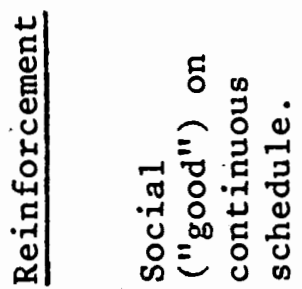

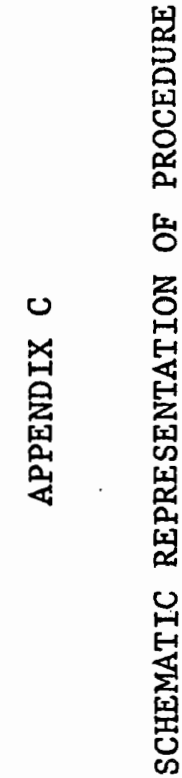
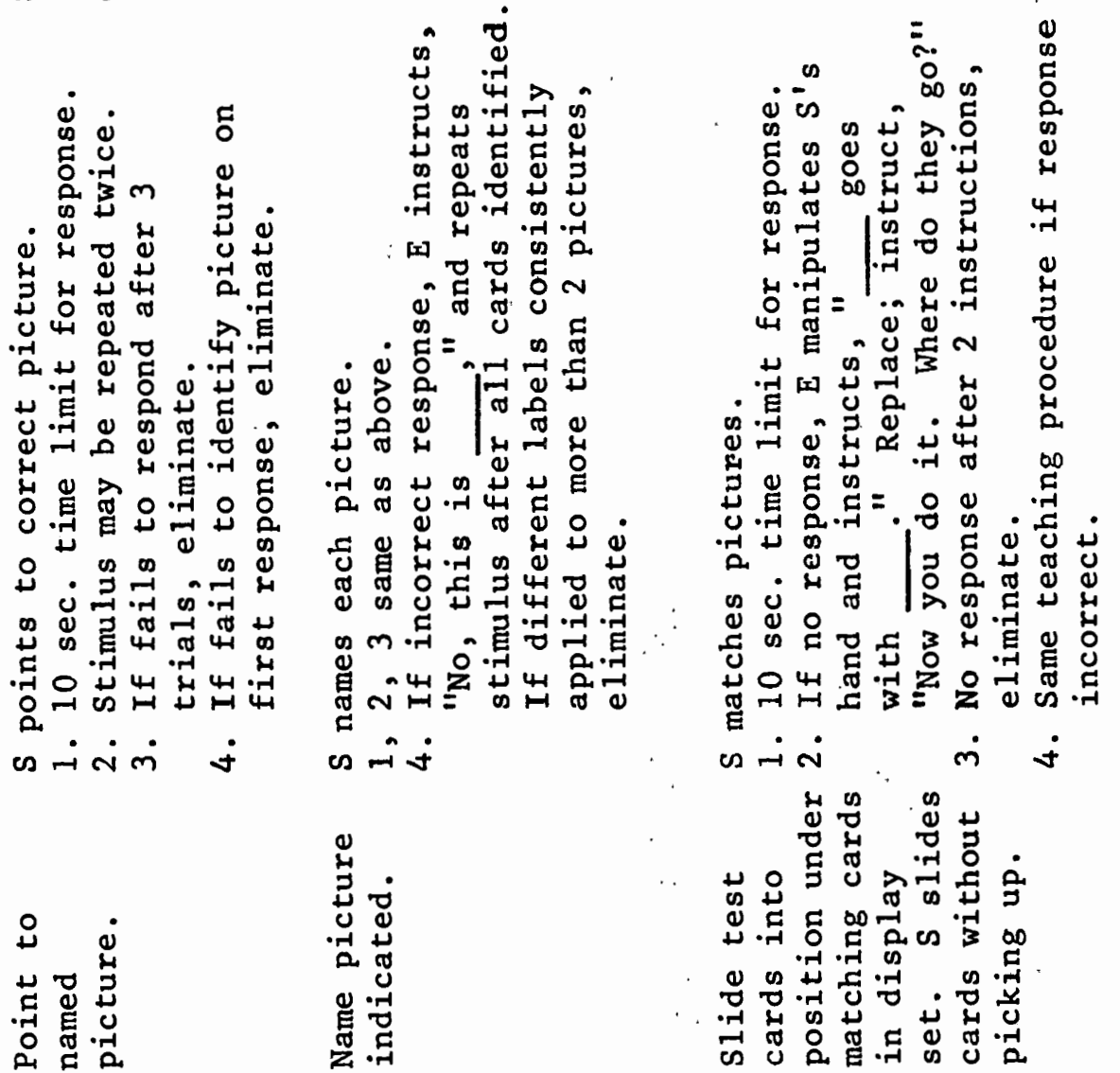

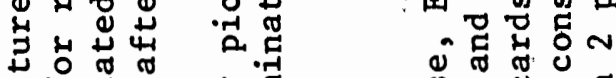

.

$\dot{0} \stackrel{0}{0}=0$ 番

年

Uึ:

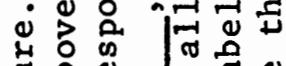

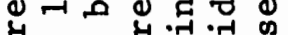

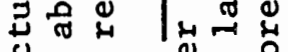

-

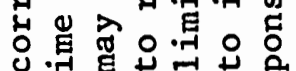

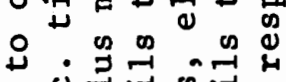

ค

ปี

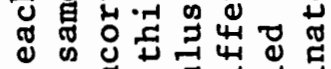

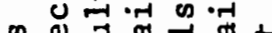

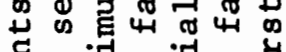

.

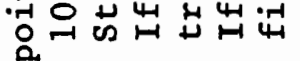

क m.

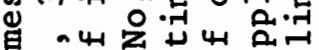

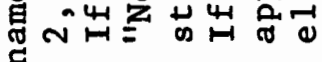

कां் $\dot{j}$ कां

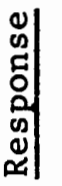

㟧

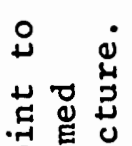

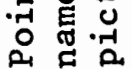

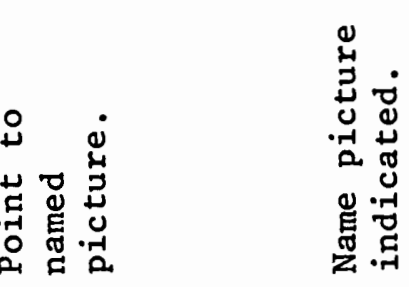

苟
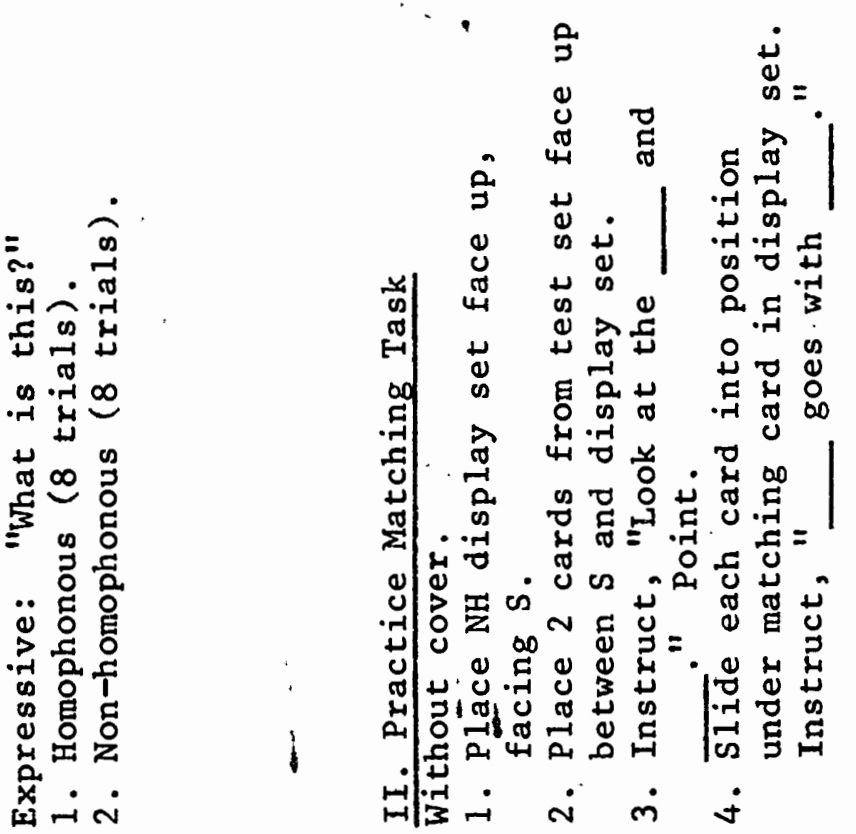


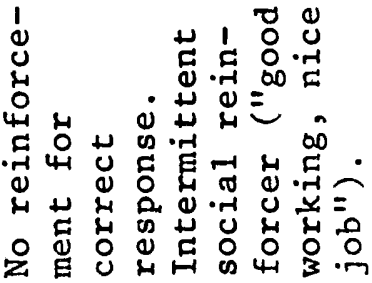

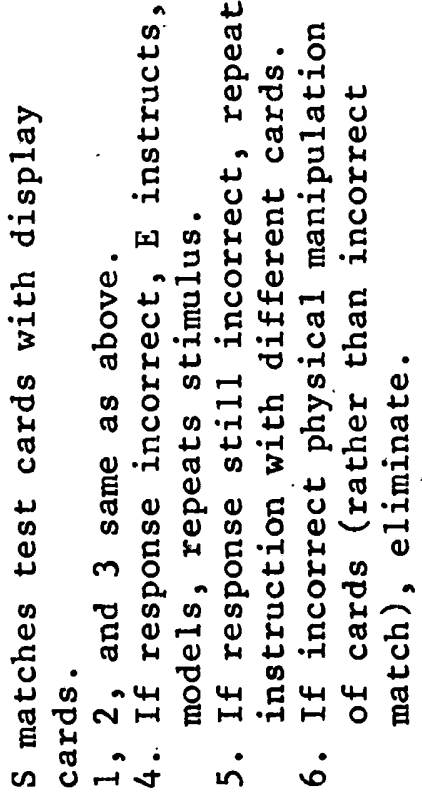

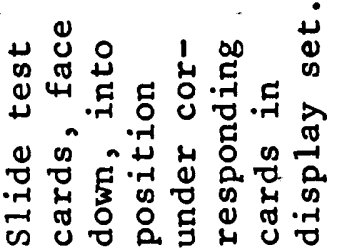

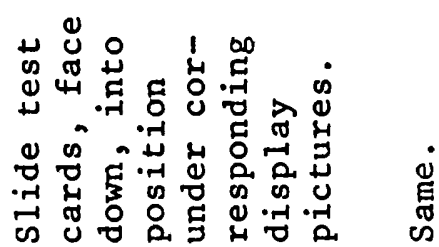



